OPEN ACCESS

Edited by:

Pung P. Hwang,

Academia Sinica, Taiwan

Reviewed by:

Yi Ta Shao,

National Taiwan University, Taiwan

Stephen D. McCormick,

University of Massachusetts Amherst,

United States

*Correspondence:

Juan Antonio Martos-Sitcha

juanantonio.sitcha@uca.es

${ }^{\dagger}$ Present address:

Laura Cádiz,

Department of Bioscience, Faculty of Science and Technology, Aarhus

University, Aarhus, Denmark

Specialty section: This article was submitted to

Aquatic Physiology,

a section of the journal

Frontiers in Physiology

Received: 16 December 2018

Accepted: 28 February 2019

Published: 21 March 2019

Citation:

Martos-Sitcha JA, Cádiz L

Gozdowska M, Kulczykowska E,

Martínez-Rodríguez $\mathrm{G}$ and

Mancera JM (2019) Arginine

Vasotocin and Cortisol Co-regulate Vasotocinergic, Isotocinergic, Stress, and Thyroid Pathways in the Gilthead

Sea Bream (Sparus aurata).

Front. Physiol. 10:261.

doi: 10.3389/fphys.2019.00261

\section{Arginine Vasotocin and Cortisol Co-regulate Vasotocinergic, Isotocinergic, Stress, and Thyroid Pathways in the Gilthead Sea Bream (Sparus aurata)}

\author{
Juan Antonio Martos-Sitcha ${ }^{1,2 *}$, Laura Cádiz' ${ }^{1 \dagger}$, Magdalena Gozdowska ${ }^{3}$, \\ Ewa Kulczykowska ${ }^{3}$, Gonzalo Martínez-Rodríguez ${ }^{2}$ and Juan Miguel Mancera ${ }^{1}$ \\ 'Department of Biology, Faculty of Marine and Environmental Sciences, Instituto Universitario de Investigación Marina, \\ Campus de Excelencia Internacional del Mar, University of Cádiz, Cádiz, Spain, ${ }^{2}$ Department of Marine Biology \\ and Aquacuture, Instituto de Ciencias Marinas de Andalucía, Consejo Superior de Investigaciones Científicas, Cádiz, Spain, \\ ${ }^{3}$ Department of Genetics and Marine Biotechnology, Institute of Oceanology, Polish Academy of Sciences, Sopot, Poland
}

In teleosts, a complex interaction between several endocrine axes modulates physiological functions related to metabolism, stress, and osmoregulation. Although many studies in fish underline the interconnection between the hypothalamicpituitary-interrenal (HPI) and hypothalamic-pituitary-thyroid (HPT) endocrine axes, their relationship with the vasotocinergic and isotocinergic systems remains unknown. The aim of the present study is therefore to shed light on the potential cross-regulations between HPT, HPI, and the vasotocinergic and isotocinergic axes in gilthead sea bream (Sparus aurata) at hypothalamic, hypophyseal, and plasma levels. Sea breams were administered with intraperitoneal slow-release implants containing different doses of vasotocin (the active peptide in vasotocinergic system) or cortisol (the last component of HPI axis). Plasma osmolality was higher in active neuropeptides vasotocin (Avt)treated fish, indicating an osmoregulatory function of this hormone. Low concentrations of Avt increased hypothalamic arginine vasotocin precursor (avt) mRNA levels and increased Avt storage in the pituitary. Avt treatment down-regulated hypothalamic arginine vasotocin receptor v1a-type (avtrv1a), suggesting a negative paracrine coregulation of the HPI axis due to the close location of avtrv1a and adrenocorticotropin hormone (Acth) cells in the anterior pituitary. Furthermore, the up-regulation observed in arginine vasotocin receptor v2-type (avtrv2) suggests their involvement in metabolic and cortisol-related pathways in the hypothalamus. The decrease in isotocin (It) pituitary storage and the up-regulation of it receptor, observed in the Avt-treated group, reinforce the idea of an interconnection between the vasotocinergic and isotocinergic systems. Cortisol and Avt administration each inhibited the HPI axis, down-regulating crh gene expression in the absence of variations in corticotropin releasing hormone binding 
protein (crhbp). Finally, both hormonal treatments activated the HPT axis via upregulation of trh and down-regulation of thrb. Our results provide evidence for strong interactions among the Avt/lt, HPI, and HPT axes of marine teleosts, particularly at the hypothalamic level.

Keywords: arginine vasotocin, cortisol, Crh, isotocin, receptors, Sparus aurata, stress, thyroid system

\section{INTRODUCTION}

The endocrine system is considered a complex net of interconnected pathways, and establishing the relevance of these pathways is critical for a correct understanding of their putative relationships. In response to stressors, the hypothalamus-pituitary-interrenal (HPI) axis is activated in a coordinated manner leading to the release of cortisol (Wendelaar Bonga, 1997). Cortisol is the main corticosteroid in teleosts and its function is related to growth, intermediary metabolism, osmotic and ionic regulation, stress, and immunity (Henderson and Garland, 1980; McCormick, 1995; Mommsen et al., 1999; Mancera and McCormick, 2007; Sherwani and Parwez, 2008). The release of cortisol is controlled by the hypothalamic corticotrophin-releasing hormone (Crh) and the Crh binding protein (Crhbp). Specifically, Crh stimulates the release of the adrenocorticotropin hormone (Acth), which is cleaved from the precursor protein proopiomelanocortin (Pomc), produced in adenohypophyseal corticotroph cells. Subsequently, Acth activates cortisol biosynthesis and releases in the interrenal cells dispersed throughout the head kidney (Wendelaar Bonga, 1997; Flik et al., 2006; Aluru and Vijayan, 2008; Bernier et al., 2009). Moreover, Crhbp is considered an antagonist of the Crh function, due to the higher affinity of Crh for Crhbp than for Crh receptors (Huising et al., 2004).

The thyroidal [hypothalamic-pituitary-thyroid (HPT)] axis is well known in mammals (Sower et al., 2009), but in fish, many aspects of its control mechanisms remain unclear (De Groef et al., 2006). Current studies indicate that the thyrotrophinreleasing hormone (Trh) controls the release of the thyroidstimulating hormone (Tsh) in teleosts, which in turn stimulates the thyroid gland to synthesize and secrete thyroid hormones (THs) [thyroxine (T4) and triiodothyronine (T3)] (Chatterjee et al., 2001; Han et al., 2004). In teleost, THs have a diverse array of physiological functions such as osmoregulation, nutrition, metabolism, and reproduction, among others (see Gorbman et al., 1983; Norris, 1997).

The interrelationship between the HPT and HPI axes in teleosts has been the subject of many studies (Dange, 1986; Redding et al., 1986; Shrimpton and McCormick, 1998). Thus, in brook charr (Salvelinus fontinalis), in vitro studies with liver homogenates demonstrated that cortisol exposure increased the hepatic conversion of T4 to T3 (Vijayan and Leatherland, 1988). In Japanese flounder (Paralichthys olivaceus), cortisol enhanced the effects of both T4 and T3 on the resorption of the dorsal fin ray (de Jesus et al., 1990). More recently, Geven et al. (2009) demonstrated that cortisol and Acth can stimulate the release of T4 from renal tissues, and T4 can inhibit the HPI axis via Crhbp in the preoptic area in the common carp (Cyprinus carpio).
Furthermore, in freshwater tilapia (Oreochromis mossambicus), exogenous T3 activated the interrenal axis to produce cortisol (Peter and Peter, 2009).

In teleosts, physiological processes such as osmoregulation, metabolism, or stress, in which HPI and HPT axes play important roles, are also mediated by the vasotocinergic and isotocinergic systems, which are homologous to the mammalian vasopressinergic and oxytocinergic pathways (Warne et al., 2002; Balment et al., 2006; Kulczykowska, 2007). However, to the best of our knowledge, the physiological interactions between the HPI and HPT axes and the vasotocinergic and isotocinergic pathways at the hypothalamic level remain unknown in fish. The vasotocinergic and isotocinergic systems are controlled by many external and internal factors, which start an endocrine process for the production of the active neuropeptides vasotocin (Avt) and isotocin (It) in different hypothalamic nuclei, with the preoptic and lateral tuberal nuclei considered the most important. Avt and It are then transported to the neurohypophysis for storage and releases into the bloodstream in response to specific stimulation (Goossens et al., 1977; Peter, 1977; van den Dungen et al., 1982). Specifically, Avt has been demonstrated to orchestrate osmoregulatory processes related to hyperosmotic environments, control of blood pressure and cardiovascular activity, reproductive behavior, brain neurotransmission, and pituitary endocrine activity (Warne et al., 2002; Balment et al., 2006; Kulczykowska, 2007). Even if the role for It is less clear, previous studies related this hormone to social status and behavior in fish (Almeida et al., 2012; Kleszczyńska et al., 2012). Moreover, recent studies in marine teleosts demonstrated that both endocrine pathways are present and affected in important tissues involved in the regulation of several acute and chronic stress events, as osmotic challenges, starvation, high stocking densities, or air exposure (Martos-Sitcha et al., 2013b, 2014a; Skrzynska et al., 2017, 2018a,b).

The purpose of this work is to unravel the interaction between the HPT and HPI axes and the vasotocinergic and isotocinergic systems in the gilthead sea bream (Sparus aurata). This species was selected as a biological model because of the available data on the endocrine mechanisms involved in stress, osmoregulation, and metabolism (Arends et al., 1999; Laiz-Carrión et al., 2002, 2005; Mancera et al., 2002; Sangiao-Alvarellos et al., 2003; Martos-Sitcha et al., 2014b; Ruiz-Jarabo et al., 2018), and due to its importance in Mediterranean aquaculture. The first specific aim was to evaluate, in a short-time course response, hypothalamic components of the vasotocinergic, isotocinergic, HPI, and HPT axes following an intraperitoneal administration of slow-release implants containing different doses of Avt or cortisol. The subsequent objective was to determine the dynamic of changes of hypophyseal Avt/It content as well as its consequences regarding 
their release, concomitantly with cortisol hormone, into the blood stream. Finally, new insights into the regulation and interconnection between different physiological and endocrine pathways are also provided.

\section{MATERIALS AND METHODS}

\section{Animals and Experimental Protocol}

Gilthead sea bream (S. aurata L., $193.2 \pm 3.5$ g body mass) juveniles were obtained from fish-farming sources (CUPIMAR, San Fernando, Cádiz, Spain) and provided by Servicios Centrales de Investigación en Cultivos Marinos (SCI-CM, CASEM, University of Cádiz, Cádiz, Spain; Operational Code REGA ES11028000312). Animals were then randomly distributed to 400-L tanks (density $\sim 3.5 \mathrm{~kg} \cdot \mathrm{m}^{-3}$ ), in an open system circuit, and acclimated for 14 days to seawater (SW, 38\% salinity), during the natural photoperiod (February-March) for the latitude $\left(36^{\circ} 31^{\prime} 44^{\prime \prime} \mathrm{N}\right)$ and constant temperature $\left(18-19^{\circ} \mathrm{C}\right)$ at the indoor wet laboratories in the Faculty of Marine and Environmental Sciences (Puerto Real, Cádiz, Spain). Fish were fed a daily ration of $1 \%$ of their body mass with commercial pellets (Dibaq-Dibroteg S.A., Segovia, Spain). All procedures were approved by the Ethics and Animal Welfare Committee of the University of Cádiz and carried out according to the Guidelines of the European Union (2010/63/UE) and the Spanish legislation (RD53/2013) for the use of laboratory animals.

\section{Experiment I: Avt Administration}

On day 0 , experimental fish $(n=63)$ allocated in six $400-\mathrm{L}$ tanks were lightly anesthetized with 2 -phenoxyethanol $\left(0.5 \mathrm{~mL} \cdot \mathrm{L}^{-1}\right.$ SW), weighed, and intraperitoneally injected (two tanks per experimental condition) with a mixture of coconut and sunflower oils (in a proportion $5: 1,5 \mu \mathrm{L} \cdot \mathrm{g}^{-1}$ body mass) alone (control, $n=21$ ) or containing different doses (0.5 or $1.0 \mu \mathrm{g} \cdot \mathrm{g}^{-1}$ body mass, $n=21$ per dose) of Avt ( $\mathrm{Arg}^{8}$-vasotocin; Sigma, Cat. \#V0130). These implants can function in a fish body for a continuous release over at least 2-6 days (Sangiao-Alvarellos et al., 2006). 2-Phenoxyethanol used here and elsewhere was selected due to its short time to induce deep anesthesia (less than $1 \mathrm{~min}$ ) without significant effects on the physiological parameters assessed (Toni et al., 2015; Priborsky and Velisek, 2018). Later, fish were recovered in their respective experimental units and maintained at the same environmental conditions as described above until sampling procedures. Both doses of Avt used have previously been shown to be effective in the activation of endocrine and osmoregulatory pathways (SangiaoAlvarellos et al., 2006). No mortality was observed in any of the experimental groups.

\section{Experiment II: Cortisol Administration}

Experimental design was performed as previously described by Cádiz et al. (2015). In short, on day 0, experimental fish $(n=42)$ from six $400-\mathrm{L}$ tanks were lightly anesthetized with 2-phenoxyethanol $\left(0.5 \mathrm{~mL} \cdot \mathrm{L}^{-1} \mathrm{SW}\right)$, weighed, and intraperitoneally injected (in triplicate tanks) with a mixture of coconut and sunflower oils (in a proportion $5: 1,5 \mu \mathrm{L} \cdot \mathrm{g}^{-1}$ body mass) alone (control, $n=21)$ or containing cortisol $\left(50 \mu \mathrm{g} \cdot \mathrm{g}^{-1}\right.$ body mass, $n=21$ ) (hydrocortisone 21-hemisuccinate sodium salt, Sigma-Aldrich, Cat. No. H2270, Madrid, Spain), and recovered as described above. No mortality was observed in any of the experimental groups.

\section{Sample Collection}

Seven fish from each experimental condition (at Experiments I and II) were deeply anesthetized with 2-phenoxyethanol (1 $\mathrm{mL} \cdot \mathrm{L}^{-1} \mathrm{SW}$ ), weighed, and sampled (blood, pituitary, and hypothalamus) at $12 \mathrm{~h}, 1$ and 3 days after hormone administration. In addition, seven to eight fish from non-treated groups were sampled on day 0 as an extra control. Blood samples were collected from the caudal blood vessels into $2 \mathrm{~mL}$ ammoniaheparinized (Sigma) syringes, and centrifuged ( 3 min at 10,000 $\mathrm{g}$ ). Plasma samples were divided into two Eppendorf tubes, for measurement of Avt, It, cortisol, and osmolality. Pituitaries were snap-frozen in liquid nitrogen and stored at $-80^{\circ} \mathrm{C}$. The two complete hypothalamic lobules (including all neuronal regions contained in this brain division) were put in a $1 / 10$-relation $\mathrm{w} / \mathrm{v}$ of RNAlater ${ }^{\mathrm{TM}}$ stabilization solution $\left(\right.$ Ambion $^{\circledR}$ ) for $24 \mathrm{~h}$ at $4^{\circ} \mathrm{C}$ and then stored at $-20^{\circ} \mathrm{C}$ until total RNA isolation.

\section{Plasma Parameters}

Plasma osmolality was measured from $10 \mu \mathrm{L}$ of each individual sample with a vapor pressure osmometer (Fiske One-Ten Osmometer, Fiske-VT, United States) and expressed as $\mathrm{mOsm} \cdot \mathrm{kg}^{-1}$.

Plasma cortisol levels were measured by enzyme-linked immunosorbent assay (EIA) adapted to microtiter plates as previously described by Martos-Sitcha et al. (2014b) for this species. In short, steroids were extracted from $5 \mu \mathrm{L}$ of plasma, and cortisol EIA standard (Cat. \#10005273), goat anti-mouse IgG monoclonal antibody (Cat. \#400002), cortisol monoclonal antibody (Cat. \#400372), and cortisol-AChE tracer (Cat. \#400370) were obtained from the Cayman Chemical Company (Michigan, United States). Standards and extracted plasma samples were run in duplicate. A standard curve was run from $2.5 \mathrm{ng} / \mathrm{mL}$ to $9.8 \mathrm{pg} / \mathrm{mL}\left(R^{2}=0.992\right)$. The lower limit of detection (98.8\% of binding, ED98.8) was $10.1 \mathrm{pg} / \mathrm{mL}$. The percentage of recovery was $95.0 \%$. The inter- and intra-assay coefficients of variation (calculated from the sample duplicates) were $0.8 \pm 0.11$ and $3.5 \pm 0.55 \%$, respectively. The cross-reactivity of the specific antibody toward intermediate steroid synthesis products was determined by the supplier [Cayman Chemical Company, Michigan, United States; cortexolone (1.6\%), 11deoxycorticosterone $(0.23 \%)$, 17-hydroxyprogesterone $(0.23 \%)$, cortisol glucuronide $(0.15 \%)$, corticosterone $(0.14 \%)$, cortisone $(0.13 \%)$, androstenedione $(<0.01 \%), 17$-hydroxypregnenolone $(<0.01 \%)$, testosterone $(<0.01 \%)]$.

\section{Quantification of mRNA Expression Levels}

In all protocols, the manufacturer's instructions were followed except where stated. Total RNA was extracted using an UltraTurrax $^{\circledR}$ T8 (IKA ${ }^{\circledR}$-Werke) from both hypothalamic lobes using 
the NucleosSpin ${ }^{\circledR}$ RNA kit (Macherey-Nagel) in a volume of $600 \mu \mathrm{L}$ of buffer RA1 contained in the kit. Genomic DNA was removed by the on-column DNase digestion at $37^{\circ} \mathrm{C}$ for $30 \mathrm{~min}$, using the rDNase (RNase-free) included in the kit. RNA quality was checked in an Agilent 2100 Bioanalyzer and with the Agilent RNA 6000 Nano Assay kit (Agilent Technologies), whereas RNA quantity was fluorimetrically measured with the Qubit $^{\circledR}$ 2.0 Fluorometer (Invitrogen ${ }^{\mathrm{TM}}$, Life Technologies). All samples processed presented an RNA Integrity Number (RIN) higher than 8.50, which was indicative of the intact RNA to be used for real-time quantitative PCR (qPCR). Primers for arginine vasotocin precursor (avt, acc. no. FR851924), isotocin (it, acc. no. FR851925), arginine vasotocin receptor v1a-type (avtrv1a, acc. no. KC195974), arginine vasotocin receptor v2type (avtrv2, acc. no. KC960488), isotocin receptor (itr, acc. no. KC195973), crh (acc. no. KC195964), crhbp (acc. no. KC195965), trh (ac. no.: KC196277), thyroid hormone receptor beta (thrb, acc. no. AY246695), and beta actin (actb, acc. no. X89920) from S. aurata (at the final concentration provided in Supplementary Table S1) were used as previously described by Martos-Sitcha et al. (2013b, 2014a,b) and Ruiz-Jarabo et al. (2018). Several calibration plots with different template concentrations in serial dilutions (from $10 \mathrm{ng}$ to $100 \mathrm{fg}$ of input total RNA) had amplification efficiencies and $r^{2}$ of $0.97-1.01$ and $0.99-$ 1.00, respectively, for all primer pairs used. Each reaction mixture $(10 \mu \mathrm{L})$ contained $0.5 \mu \mathrm{L}$ of each specific forward and reverse primers concentration, and $5 \mu \mathrm{L}$ of PerfeCTa SYBR $^{\circledR}$ Green FastMix ${ }^{\mathrm{TM}}$ (Quanta Biosciences). Reactions were conducted in semi-skirted twin.tec real-time PCR plates 96 (Eppendorf) covered with adhesive Masterclear real-time PCR Film (Eppendorf), and run in an Eppendorf Mastercycler ep realplex ${ }^{2} \mathrm{~S}$. The PCR profile was as follows: $95^{\circ} \mathrm{C}, 10 \mathrm{~min}$; $\left[95^{\circ} \mathrm{C}, 30 \mathrm{~s} ; 60^{\circ} \mathrm{C}, 45 \mathrm{~s}\right] \times 40$ cycles; melting curve [60$\left.95^{\circ} \mathrm{C}, 20 \mathrm{~min}\right], 95^{\circ} \mathrm{C}, 15 \mathrm{~s}$. The melting curve was used to ensure that a single product was amplified and to check for the absence of primer-dimer artifacts. Results were normalized to $S$. aurata $\beta$-actin ( $a c t b, \mathrm{X} 89920)$ owing to its low variability (less than $0.3 \mathrm{C}_{\mathrm{T}}$, ranged between 13.81 and $14.07 \mathrm{C}_{\mathrm{T}}$ ) among fish of both experimental conditions and sub-trials. Relative gene quantification was performed using the $\Delta \Delta \mathrm{C}_{\mathrm{T}}$ method (Livak and Schmittgen, 2001). This manuscript follows the ZFIN Zebrafish Nomenclature Guidelines for gene and protein names and symbols ${ }^{1}$.

\section{Avt and It Content in Plasma and Pituitary}

The Avt and It content in the plasma and pituitary gland were determined using high-performance liquid chromatography (HPLC) with fluorescence detection, preceded by solid-phase extraction (SPE) based on Gozdowska et al. (2006) and MartosSitcha et al. (2013b). Thus, plasma samples (1 mL each) were acidified with $1 \mathrm{M} \mathrm{HCl}(100 \mu \mathrm{L})$ and centrifuged at $6000 \mathrm{~g}$ for $20 \mathrm{~min}$ at $4^{\circ} \mathrm{C}$, whereas frozen pituitaries were weighed $(441 \pm 11 \mu \mathrm{g})$ and sonicated in $0.5 \mathrm{~mL}$ Milli-Q water

${ }^{1}$ https://wiki.zfin.org/display/general/ZFIN+Zebrafish+Nomenclature+ Guidelines
(Microson ${ }^{\mathrm{TM}} \mathrm{XL}$, Misonix, United States). After that, the SPE protocol was carried out for the Avt and It extraction. The resulting eluate was evaporated to dryness using a Turbo Vap LV Evaporator (Caliper Life Scence, United States) and samples were frozen and stored at $-80^{\circ} \mathrm{C}$ until HPLC analysis. The samples were then re-suspended in $40 \mu \mathrm{L} \quad 0.1 \%$ trifluoroacetic acid (TFA) and then divided into two aliquots for duplicate analysis. Pre-column derivatization of Avt and It in $20 \mu \mathrm{L}$ samples was performed using $3 \mu \mathrm{L}$ 4-fluoro-7-nitro-2,1,3-benzoxadiazole (NBD-F) solution (30 mg NBD-F in $1 \mathrm{~mL}$ of acetonitrile) in a mixture of $20 \mu \mathrm{L}$ phosphate buffer $(0.2 \mathrm{M}, \mathrm{pH} 9.0)$ and $20 \mu \mathrm{L}$ acetonitrile. The solution was heated to $60^{\circ} \mathrm{C}$ for $3 \mathrm{~min}$ in a dry heating block and cooled on ice. Next, $4 \mu \mathrm{L} 1 \mathrm{M} \mathrm{HCl}$ was added. Derivatized samples were measured using an Agilent 1200 Series Quaternary HPLC System (Agilent Technologies, United States). Chromatographic separation was achieved using Agilent ZORBAX Eclipse XDB-C18 columns (150 mm $\times 4.6 \mathrm{~mm}$ I.D., $5 \mu \mathrm{m}$ particle size). A gradient elution system was used to separate the derivatized peptides. The mobile phase consisted of solvent $\mathrm{A}\left(0.1 \%\right.$ TFA in $\left.\mathrm{H}_{2} \mathrm{O}\right)$ and solvent $\mathrm{B}(0.1 \%$ TFA in acetonitrile: $\mathrm{H}_{2} \mathrm{O}$ (3:1). A linear gradient was $45-70 \%$ eluent $B$ in $20 \mathrm{~min}$. Flow rate was set at $1 \mathrm{~mL} / \mathrm{min}$ and the column temperature at $20^{\circ} \mathrm{C}$. The injection volume was $67 \mu \mathrm{L}$. Fluorescence detection was carried out at $530 \mathrm{~nm}$ with excitation at $470 \mathrm{~nm}$.

\section{Statistics}

After the normality and homogeneity of variances where checked, statistical differences were analyzed by two-way ANOVA with treatment (control, hormone administration) and time (day 0 , $12 \mathrm{~h}$, days 1 and 3 ) as main factors. These analyses were followed by Tukey's test post hoc comparisons using GraphPad Prism ${ }^{\circledR}$ (v.5.0b) software. Statistical significance was accepted at $P \leq 0.05$. Statistical parameters $(P$-value and $F$ ) obtained from two-way ANOVA analysis in both sub-experiments are provided in Supplementary Table S2. Principal component analyses (PCAs) were performed using individual gene expression values and hormonal concentrations, and the default prcomp $\mathrm{R}$ function. Visualizations were constructed using the factoextra (v1.0.4) and gplots (v3.0.1) R package.

\section{RESULTS}

\section{Effects of Avt Administration Plasma Osmolality}

Time-course changes in plasma osmolality response of sea bream juveniles to different doses of Avt are shown in Figure 1. In both doses, plasma osmolality increased its values $12 \mathrm{~h}\left(1.0 \mu \mathrm{g} \cdot \mathrm{g}^{-1}\right.$ body mass) or 3 days ( $0.5 \mu \mathrm{g} \cdot \mathrm{g}^{-1}$ body mass) after treatment, maintaining statistically higher values compared to the control fish at the end of the experiment. In the control group, no significant changes were observed during the whole experiment.

\section{Vasotocinergic and Isotocinergic Systems}

The time-course responses of hypothalamic avt and it expression to Avt treatment are shown in Figures 2A,B. In control fish, 


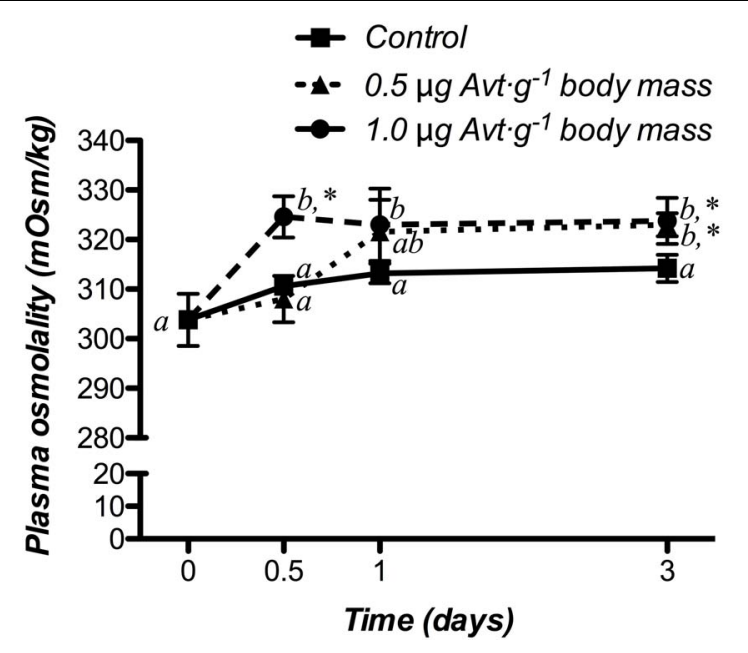

FIGURE 1 | Time-course of changes in plasma osmolality in SW-adapted gilthead sea breams implanted with vegetable oil (mixture 5:1 coconut and sunflower oils) alone (control) or containing different doses of $\mathrm{Arg}^{8}$-vasotocin (Avt, 0.5 or $1 \mu \mathrm{g} \mathrm{g}^{-1}$ body mass). Values are represented as mean \pm SEM ( $n=7$ fish per group). Significant differences among sampling points at the same Avt concentration are identified with different letters, whereas different symbols showed differences between groups at the same time $(P<0.05$, two-way ANOVA followed by Tukey's test).

there were no variations in avt expression during the experiment, whereas it mRNA levels were significantly higher at day 3 posttreatment, when compared to non-treated fish (day 0). Avt treatment produced an increase in hypothalamic avt mRNA levels at the end of the experiment (day 3), but only at the lower dose of $0.5 \mu \mathrm{g} \cdot \mathrm{g}^{-1}$ body mass. The mRNA expression of it did not show time-course variations after administration of both doses of Avt.

Changes in hypophyseal storage of Avt and It, in response to Avt treatment, are presented in Figures 2C,D. In the control group, Avt and It storage did not change during the experiment. Fish administered with $0.5 \mu \mathrm{g} \cdot \mathrm{g}^{-1}$ of Avt increased the Avt storage in the pituitary $12 \mathrm{~h}$ post-treatment, when compared to non-treated fish (day 0 ), and then they recovered to control levels at day 1, with a strong interaction between both factors. It content showed a significant time- and dose-dependent decrease after $12 \mathrm{~h}\left(1.0 \mu \mathrm{g} \mathrm{g}^{-1}\right.$ body mass of Avt) or 3 days $\left(0.5 \mu \mathrm{g} \cdot \mathrm{g}^{-1}\right.$ body mass of Avt) of treatment, maintaining it until the end of the experiment with a significant interaction between both factors.

The time-course changes in plasma Avt and It levels after Avt treatment are shown in Figures 2E,F. In the control group, both nonapeptides did not significantly vary over time. However, in both Avt-treated groups, plasma Avt levels were significantly lower when compared to non-treated fish (day 0 ) at $24 \mathrm{~h}$, or with respect to the control group from $24 \mathrm{~h}$ onward (Figure 2E). On the other hand, plasma It levels increased in animals treated with the highest dose of Avt ( $1.0 \mu \mathrm{g} \cdot \mathrm{g}^{-1}$ body mass of Avt) $12 \mathrm{~h}$ postadministration, decreasing significantly from day 1 until the end of the experiment (Figure $2 \mathbf{F}$ ). In addition, the administration of $0.5 \mu \mathrm{g} \mathrm{g}^{-1}$ body mass of Avt resulted in a significant timedependent reduction of plasma It, with respect to the control group from day 1 onward (Figure 2F).

Changes in Avt and It receptor gene expression (avtrv1a, avtrv2, and itr) in the hypothalamus are shown in Figure 3. There were no significant changes in avtrs or itr mRNA expression in the control group. However, avtrv1a significantly decreased during the first $12 \mathrm{~h}$ in both groups treated with 0.5 or $1.0 \mu \mathrm{g}$ $\mathrm{g}^{-1}$ body mass of Avt, returning to baseline values after that (Figure 3A), showing a significant interaction between both factors. Moreover, at the end of the trial (day 3), avtrv2 mRNA levels significantly increased in both Avt treated groups when compared to non-treated fish at day 0 , with its highest expression after the administration of $1.0 \mu \mathrm{g} \mathrm{g}^{-1}$ body mass of Avt, with respect to the control fish (Figure 3B). In addition, a significant time- and dose-dependent increase was also observed for the itr mRNA levels from 1 day $\left(1.0 \mu \mathrm{g} \mathrm{g}^{-1}\right.$ body mass of Avt) or day $3\left(0.5 \mu \mathrm{g} \mathrm{g}^{-1}\right.$ body mass of Avt) after hormonal administration (Figure 3C).

\section{HPI Axis}

Hypothalamic crh mRNA levels did not show variations over time in the control group, whereas Avt administration produced a significant decrease with respect to the non-treated fish (day 0 ) from day 1 onward in both 0.5 and $1.0 \mu \mathrm{g} \cdot \mathrm{g}^{-1}$ body mass Avt treatments (Figure 4A), being also significantly lower when compared to the control group at the end of the trial. In addition, no variations in hypothalamic crhbp mRNA levels were observed in any of the three groups during the 3 days of the experiment (Figure 4B).

Plasma cortisol levels did not change in the control group but increased in fish administered with $0.5 \mu \mathrm{g} \cdot \mathrm{g}^{-1}$ body mass at day 1 post-administration. In addition, treatment with $1.0 \mu \mathrm{g} \cdot \mathrm{g}^{-1}$ body mass of Avt showed a significant decrease in plasma cortisol levels at day 3 (Figure 4C).

\section{Thyroid System}

The time course responses of hypothalamic $\operatorname{trh}$ and $\operatorname{tr} \beta$ mRNA levels did not show variations in the control group (Figure 5). Both Avt doses ( 0.5 and $1 \mu \mathrm{g} \cdot \mathrm{g}^{-1}$ body mass) produced a significant decrease in trh mRNA levels with respect to the nontreated fish (day 0 ) from $12 \mathrm{~h}$ to day 1 and also when compared to the control group, returning to control levels at day 3 postadministration (Figure 5A). A clear interaction between both factors showed a temporary increase in $\operatorname{tr} \beta$ mRNA expression only at $12 \mathrm{~h}$ post-administration in fish treated with $0.5 \mu \mathrm{g}$ Avt $\cdot \mathrm{g}^{-1}$ body mass, whereas those fish treated with $1.0 \mu \mathrm{g}$ Avt $\cdot \mathrm{g}^{-1}$ body mass maintained higher values during the 3 days that the experiment lasted (Figure 5B).

\section{Effects of Cortisol Administration HPI Axis}

Hypothalamic crh and crhbp mRNA changes after cortisol administration are presented in Figure 6. crh gene expression did not show significant variations in the control group, whereas $50 \mu \mathrm{g}$ cortisol $\cdot \mathrm{g}^{-1}$ body mass decreased its values from $12 \mathrm{~h}$ post-administration until the end of the experiment ( 3 

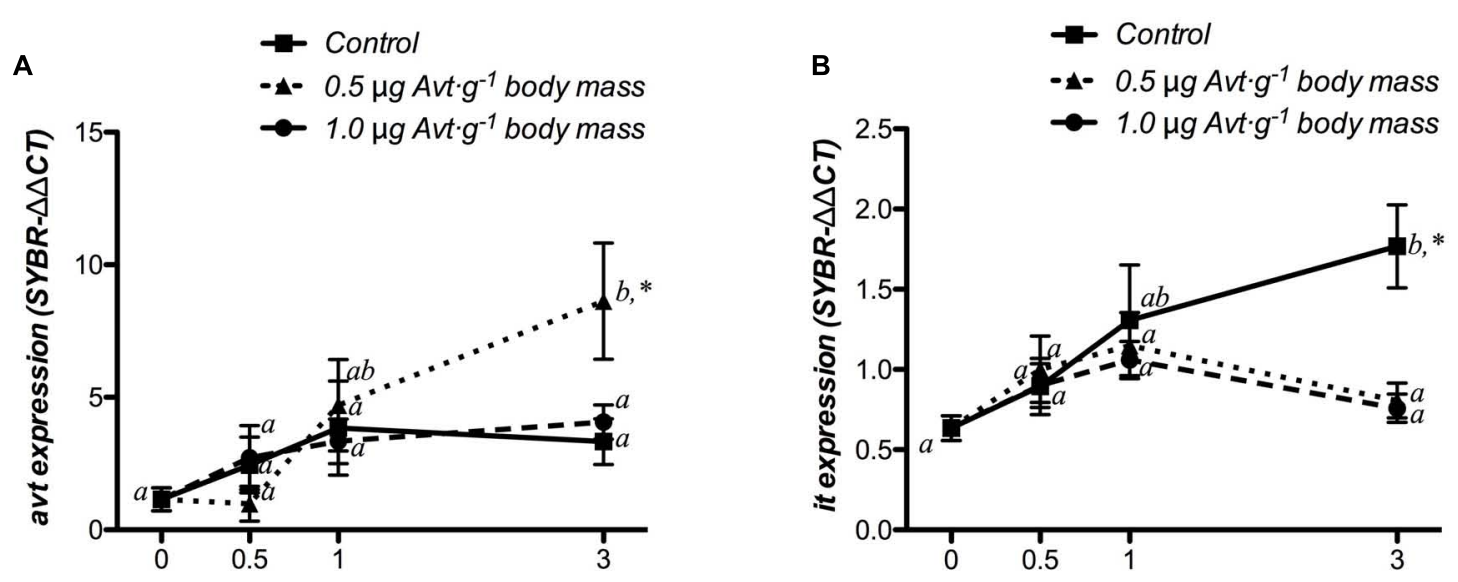

C

D
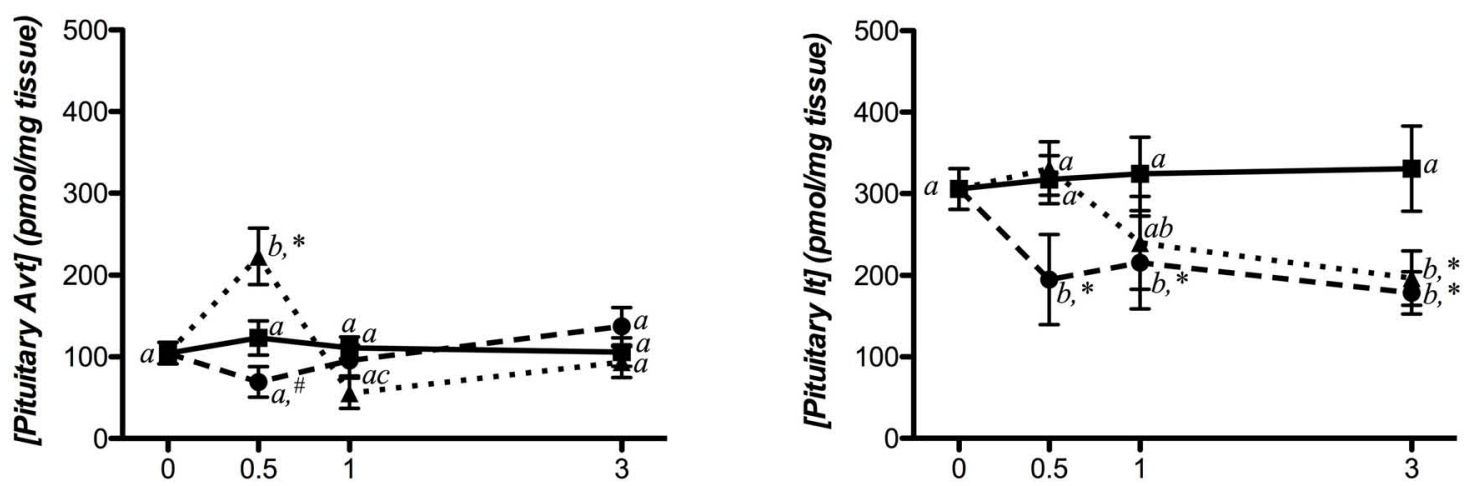

E

$\mathbf{F}$
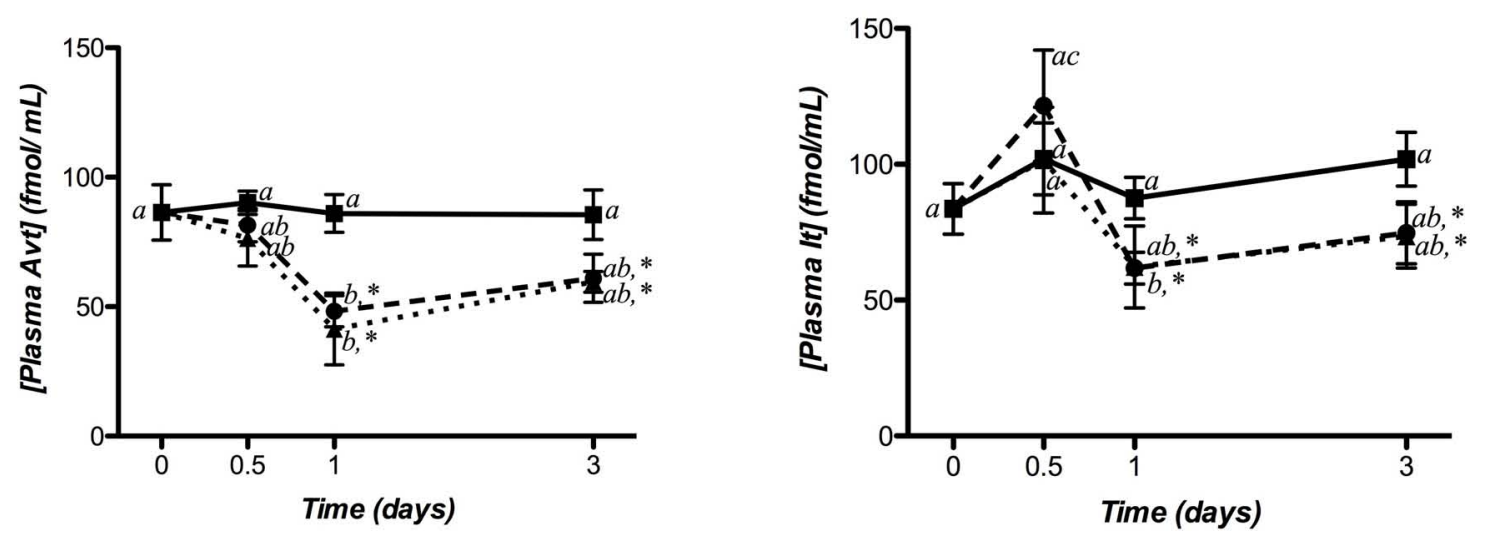

FIGURE 2 | Time-course of changes in hypothalamic avt (A) and it (B) mRNA expression, hypophyseal Avt (C) and It (D) storage, and plasma Avt (E) and It (F) levels in SW-adapted gilthead sea breams implanted with vegetable oil (mixture 5:1 coconut and sunflower oils) alone (control) or containing different doses of Arg $^{8}$-vasotocin (Avt, 0.5 or $1 \mathrm{\mu g} \mathrm{g}^{-1}$ body mass). Values are represented as mean $\pm \mathrm{SEM}$ ( $n=7$ fish per group). Further details as described in the legend of Figure 1.

days) when compared to both the non-treated (day 0) and the control fish (Figure 6A). Moreover, crhbp mRNA levels did not differ in the control and the cortisol-treated fish during the experiment (Figure 6B).

\section{Thyroid System}

Changes in trh and thrb mRNA expression at hypothalamic level are shown in Figure 7. The control fish did not show variations in either genes during the experiment. In addition, 


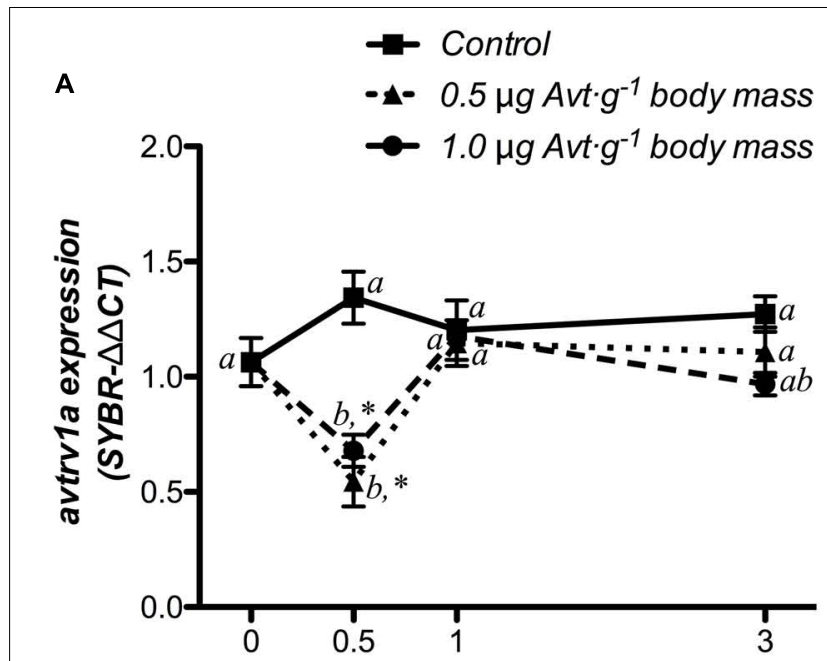

B

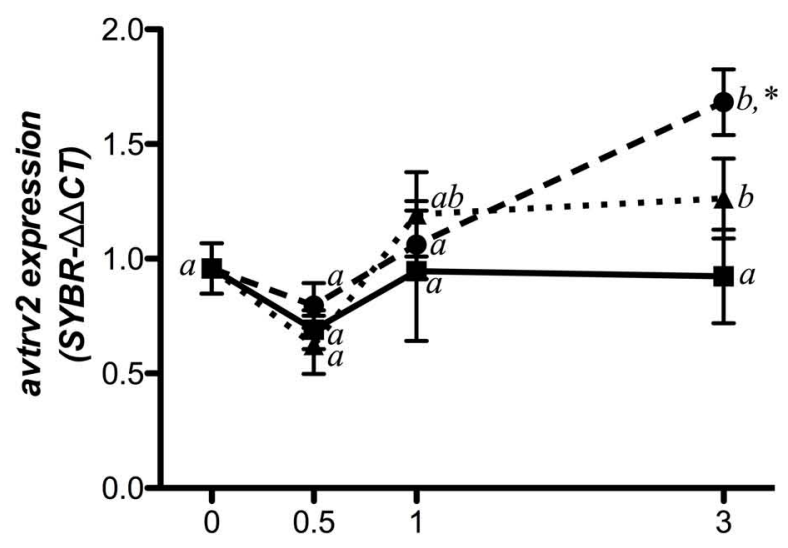

C

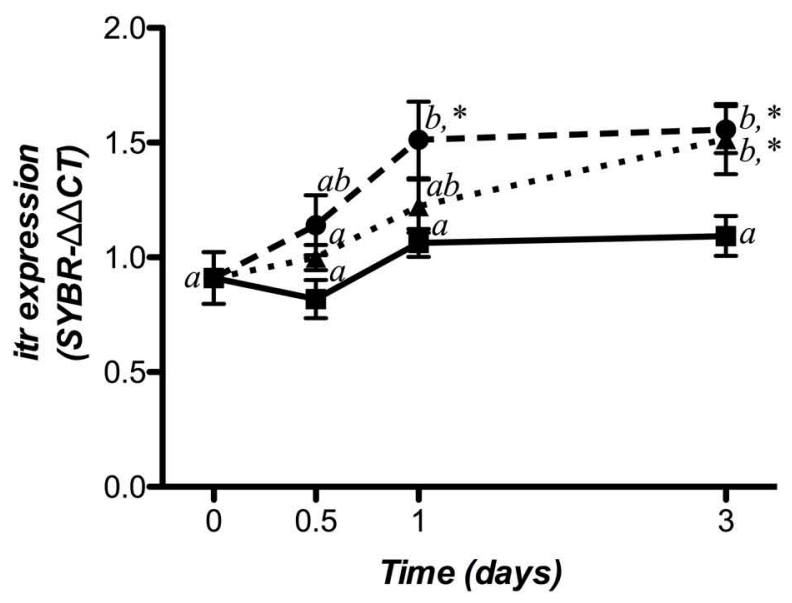

FIGURE 3 | Time-course of changes on hypothalamic avtrv1a (A), avtrv2 (B), and itr (C) mRNA expression in SW-adapted gilthead sea breams implanted with vegetable oil (mixture 5:1 coconut and sunflower oils) alone (control) or containing different doses of $\mathrm{Arg}^{8}$-vasotocin (Avt, 0.5 or $1 \mu \mathrm{g} \mathrm{g}^{-1}$ body mass). Values are represented as mean \pm SEM ( $n=7$ fish per group). Further details as described in the legend of Figure 1.

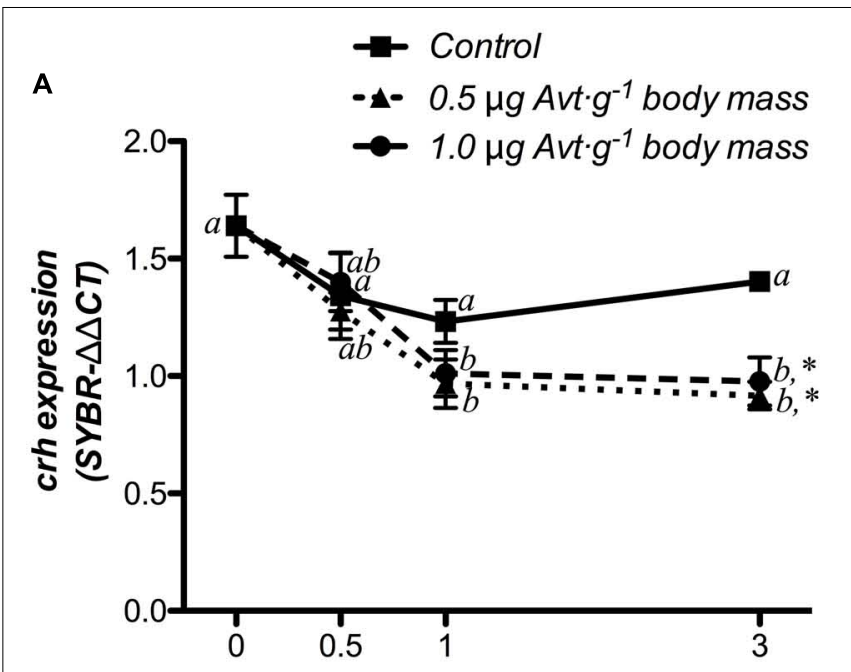

B

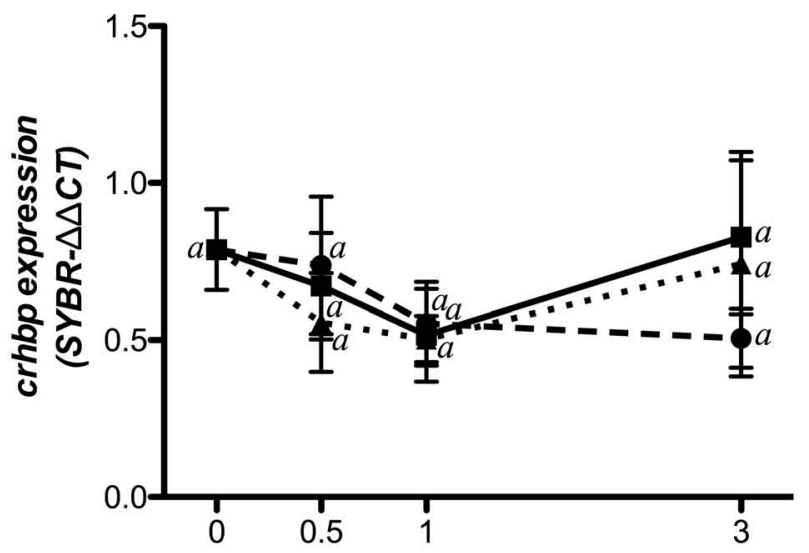

C

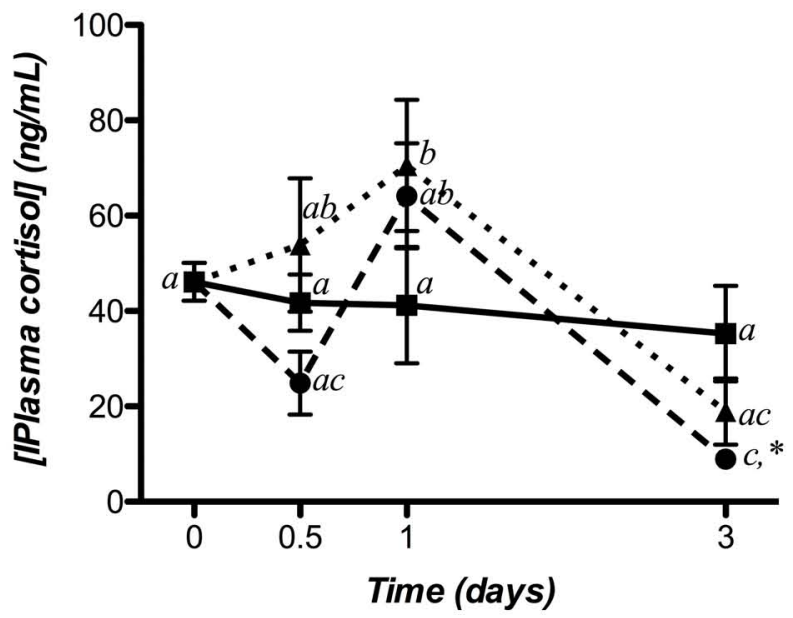

FIGURE 4 | Time-course of changes on hypothalamic crh (A) and crhbp (B) mRNA expression, as well as on plasma cortisol levels (C), in SW-adapted gilthead sea breams implanted with vegetable oil (mixture 5:1 coconut and sunflower oils) alone (control) or containing different doses of $\mathrm{Arg}^{8}$-vasotocin (Avt, 0.5 or $1 \mu \mathrm{g} \mathrm{g}^{-1}$ body mass). Values are represented as mean $\pm \mathrm{SEM}$ ( $n=7$ fish per group). Further details as described in the legend of Figure 1. 


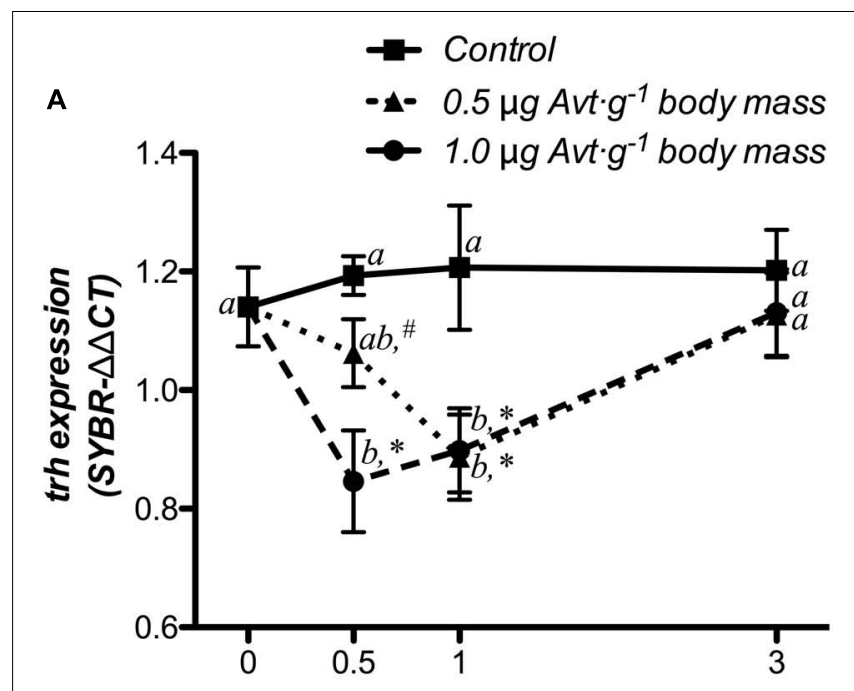

B

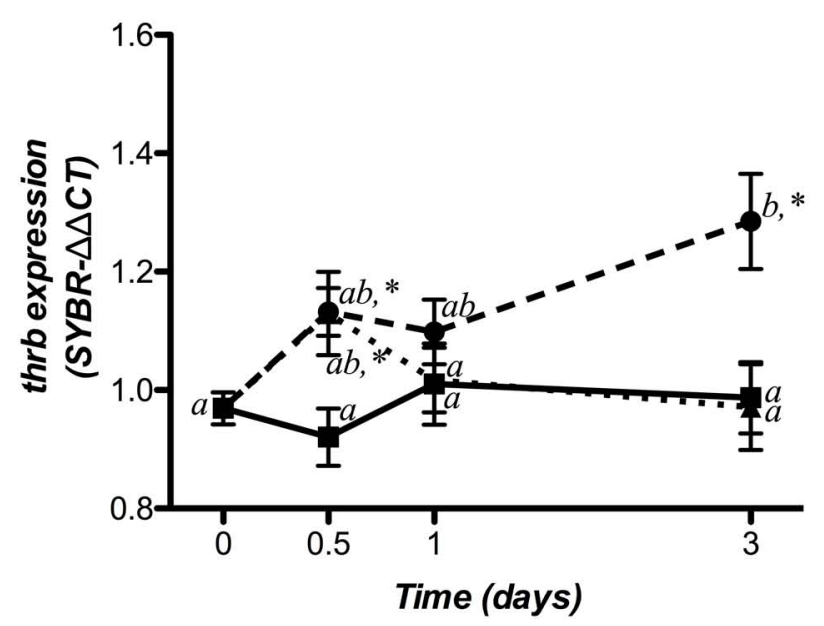

FIGURE 5 | Time-course of changes on hypothalamic trh (A) and thrb (B) mRNA expression in SW-adapted gilthead sea breams implanted with vegetable oil (mixture 5:1 coconut and sunflower oils) alone (control) or containing different doses of $\mathrm{Arg}^{8}$-vasotocin (Avt, 0.5 or $1 \mu \mathrm{g} \mathrm{g}^{-1}$ body mass). Values are represented as mean $\pm \operatorname{SEM}$ ( $n=7$ fish per group). Further details as described in the legend of Figure $\mathbf{1 .}$

doses of $50 \mu \mathrm{g} \mathrm{g}^{-1}$ body mass of cortisol, down-regulated trh mRNA levels at $12 \mathrm{~h}$ post-treatment, when compared to both the non-treated (day 0) and control fish, returning to basal values after that (Figure 7A). Moreover, gene expression of thrb showed a significant increase at $12 \mathrm{~h}$ post-administration, which was statistically higher than both the non-treated fish (day 0) and the control group. Then, thrb mRNA levels decreased until the end of the trial, showing lower values at day 3 than those observed in control fish with a significant interaction between both factors (Figure 7B).

\section{PCA Analysis}

The general PCA of all genes and hormonal parameters considered together, as well as the dataset previously published

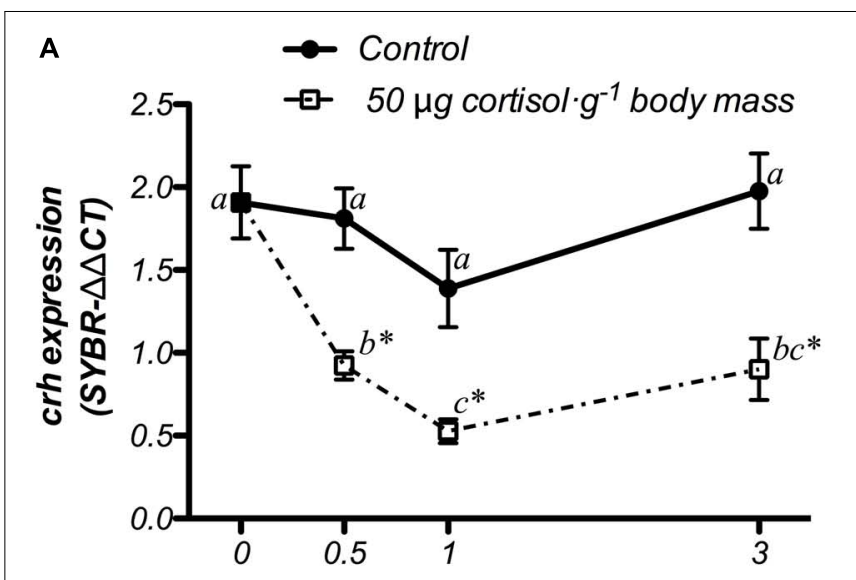

B

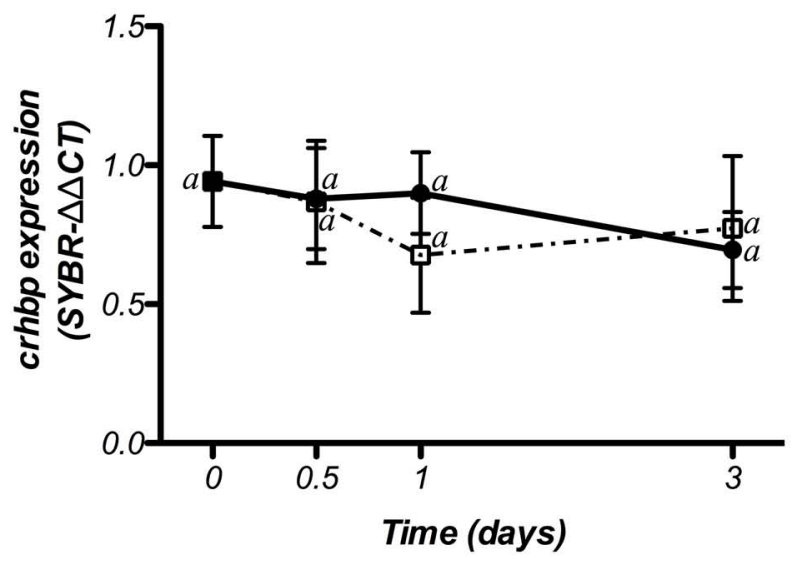

FIGURE 6 | Time-course of changes on hypothalamic crh (A) and crhbp (B) mRNA expression in SW-adapted gilthead sea breams implanted with vegetable oil (mixture 5:1 coconut and sunflower oils) alone (control) or containing cortisol (50 $\mathrm{ug} \mathrm{g}^{-1}$ body mass). Values are represented as mean \pm SEM ( $n=7-8$ fish per group). Significant differences among sampling points at the same treatment (control or cortisol) are identified with different letters, whereas different symbols showed differences between groups at the same time $(P<0.05$, two-way ANOVA followed by Tukey's test).

by our group (Cádiz et al., 2015) for the sub-trial related to cortisol injection, showed a clear separation in the two principal components, which explains in total $88.56 \%$ of the variability (Figure 8), where the effect of hormonal treatment (cortisol or Avt) seems to be explained by PC1 (49.87\%), while the timecourse effect appears to be more evident in PC2 (38.69\%).

\section{DISCUSSION}

The putative regulation and interaction between the vasotocinergic, isotocinergic, HPI, and HPT axes has not been widely studied in fish (Larsen et al., 1998; Batten et al., 1999; Geven et al., 2006; Cádiz et al., 2015). Thus, the present study highlights the complex regulation of these endocrine pathways 


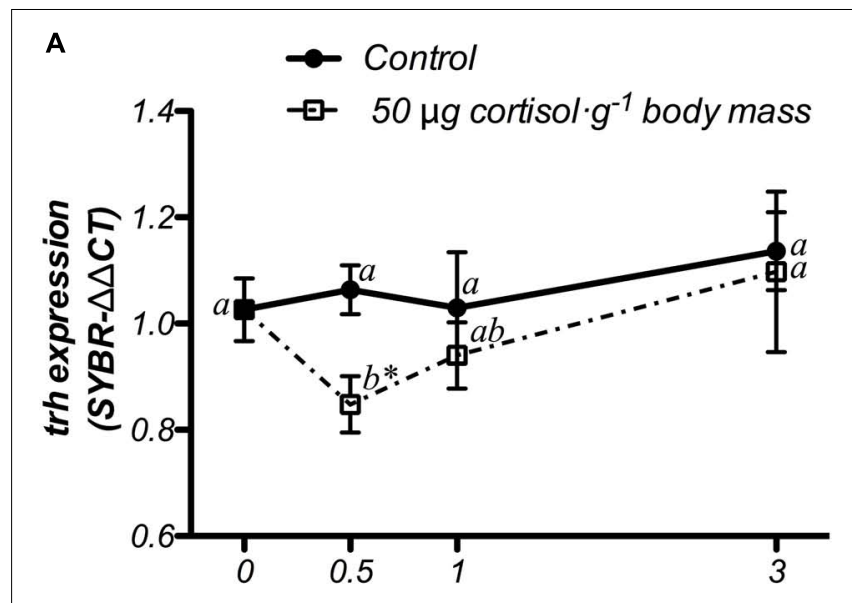

B

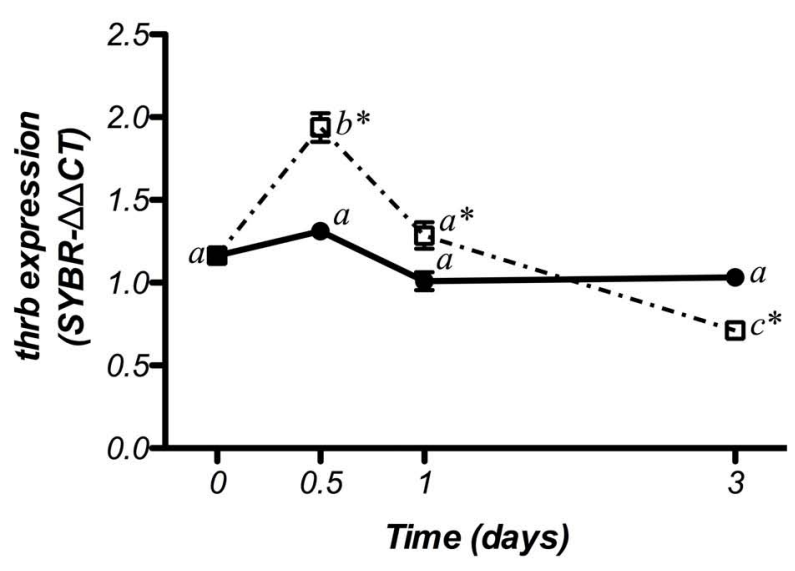

FIGURE 7 | Time-course of changes on hypothalamic trh (A) and thrb (B) mRNA expression in SW-adapted gilthead sea breams implanted with vegetable oil (mixture 5:1 coconut and sunflower oils) alone (control) or containing cortisol (50 $\mu \mathrm{g} \mathrm{g}^{-1}$ body mass). Values are represented as mean \pm SEM ( $n=7-8$ fish per group). Further details as described in the legend of Figure 6 .

mediated by cortisol and Avt hormones. Slow-release implants of coconut oil containing Avt ( 0.5 or $1.0 \mu \mathrm{g} \cdot \mathrm{g}^{-1}$ body mass) or cortisol (50 $\mu \mathrm{g} \cdot \mathrm{g}^{-1}$ body mass) successfully evoke changes in physiological parameters related to osmoregulation, stress, and metabolism in the gilthead sea bream (S. aurata) (Laiz-Carrión et al., 2002, 2003; Sangiao-Alvarellos et al., 2006; Cádiz et al., 2015). In fact, some of the up-stream players of the vasotocinergic and isotocinergic pathways, concomitantly with circulating levels of plasma cortisol, have recently been demonstrated to be affected by external cortisol administration in this model species (Cádiz et al., 2015). Moreover, as we will describe below for each sub-trial performed, it should be noted that our PCA analysis strongly suggests the cooperation of both Avt and cortisol endocrine players in terms of the direction of deviations with respect to the control groups, although the magnitude of changes seems to be produced in a more powerful way through cortisol administration (Figure 8). Thus, the clear parallelism described herein, regarding the stimulatory or inhibitory response independently caused by each hormone, reveals that their physiological actions can be considered to potentiate or trade-off the physiological action required in a complex net of molecular, biochemical, and endocrine interconnections, where the timedependent effect caused by these hormones after treatment must be attended to in addition to the doses administered (see Supplementary Table S2).

It was not surprising to observe increased plasma osmolality in fish treated with Avt due to the well-known osmoregulatory function of hypothalamic nonapeptides such as Avt and AVP. Previous studies in gilthead sea bream treated with Avt and transferred to hypersaline water already showed an increase in their plasma osmolality levels (Sangiao-Alvarellos et al., 2006). Moreover, the higher osmolality observed herein in SW-acclimated fish in a time- and dose-dependent manner, demonstrate the activation of those mechanism needed during the adaptive period at the molecular and protein level for this hormone after salinity transfers (Martos-Sitcha et al., 2013b), were the contribution of ion absorption demonstrated ex vivo by Avt administration can be highly mediated by different portions of the intestine (i.e., anterior intestine and rectum) mainly achieved via the apical $\mathrm{Na}-\mathrm{K}-2 \mathrm{Cl}(\mathrm{Nkcc} 2)$ co-transporter (Martos-Sitcha et al., 2013a). Our results also found an upregulation of hypothalamic avt gene expression and hypophyseal Avt accumulation in fish administered with $0.5 \mu \mathrm{g} \mathrm{g}^{-1}$ body mass of Avt, which was not observed after the administration of $1 \mu \mathrm{g} \mathrm{g}^{-1}$ body mass of Avt. This finding suggests that administration of a low dose of Avt triggers the first step of the stress response, mediated by the vasotocinergic system during the adaptive period, which homeostasis can promptly restore through the combination of internal production and external administration of this hormone. The significant decrease in plasma Avt, in spite of its external administration, could be explained by a combination of (i) hormonal degradation by several peptidases, which present high activity levels in the plasma of the gilthead sea bream (Agirregoitia et al., 2005), (ii) its removal mediated by renal clearance due to its high concentration in the bloodstream (Amer and Brown, 1995), and (iii) its elimination by binding to specific receptors in target tissues to cope with physiological challenges. This last hypothesis is supported by the activation of the avt receptors (avtrvla and avtrv2) in Avt treated fish. This happens not only at a central level (present results), but also in peripheral organs/tissues. In gills, opercular epithelium and the gastrointestinal tract, Avt receptors orchestrate several osmoregulatory functions related to ion transport and water absorption (Martos-Sitcha et al., 2013a, 2014a, 2015), whereas in the liver, gills, and the brain, metabolic changes related to energy repartitioning processes occurred during an activation of the vasotocinergic system (SangiaoAlvarellos et al., 2004, 2006). This pattern of response in plasma Avt, as well as in the hypothalamic mRNA expression of both avt receptors, has also previously been observed in the gilthead sea bream after cortisol administration (Cádiz et al., 2015). Thus, the down-regulation observed in avtrv1a expression when these hormones (cortisol, Cádiz et al., 2015; or Avt, present results) are administrated, will mirror a stress situation induced by a hormonal challenge. This supports the role of the vasotocinergic 


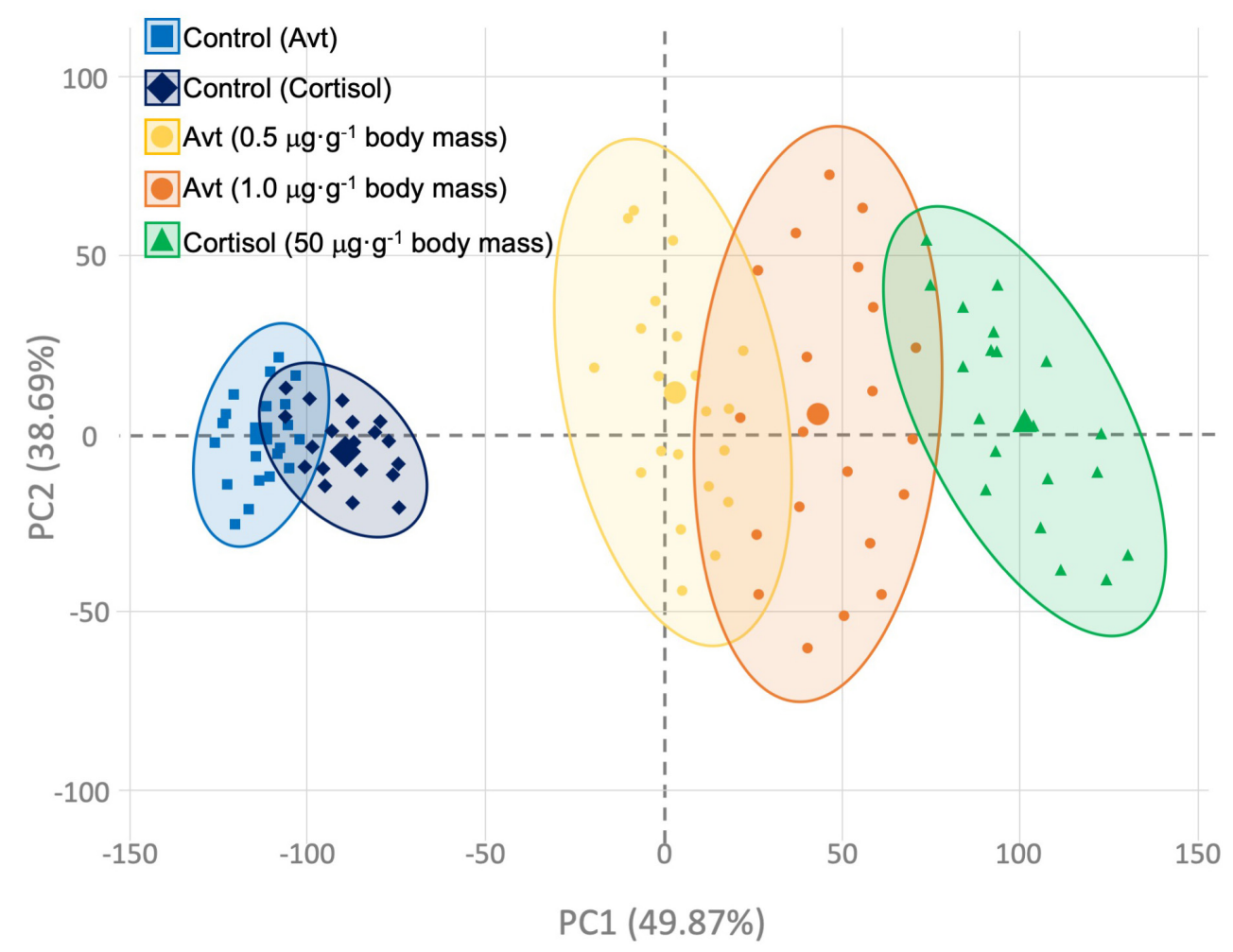

FIGURE 8 | Principal component analysis (PCA) constructed using individual gene expression values and hormonal concentrations of those fish implanted with vegetable oil (mixture 5:1 coconut and sunflower oils) alone (control; blue squares and diamonds) or containing different doses of Arg $^{8}$-vasotocin (0.5 $\mu \mathrm{g}$ Avt $\mathrm{g}^{-1}$

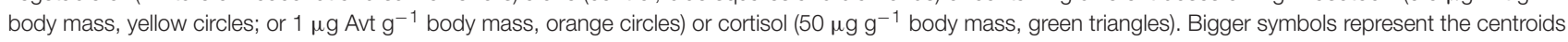
for each group's ellipse.

system in the co-regulation of the HPI axis by negative feedback processes via avtrv1a, which can target the anterior pituitary, where Acth cells are also located (Antoni, 1984; Moons et al., 1989). Moreover, increased mRNA levels of avtrv2 in the Avttreated groups indicate that gene expression of this receptor is increased to co-regulate the HPI axis, as clearly shown by elevated plasma cortisol levels $24 \mathrm{~h}$ after Avt administration. In this regard, the participation of each pathway seems to be carried out sequentially, and our results reinforce the idea about the regulation of both (i) metabolic (Sangiao-Alvarellos et al., 2004, 2006) and (ii) cortisol cascade (Cádiz et al., 2015) pathways in the hypothalamus, highlighting an important upstream function at least during the first days of treatment. Moreover, the participation of both Avt receptors in the orchestration of hypothalamic function has recently been demonstrated after several stress-related challenges such as salinity transfer, high stocking densities, starving, or air exposure, where an activation of both vasotocinergic and HPI axes is produced (Martos-Sitcha et al., 2014a; Skrzynska et al., 2017, 2018a,b).

The present study also showed a decrease in It pituitary storage in the Avt-treated group 12-24 h post-administration. This finding, together with the absence of the up-regulation observed in it mRNA expression of control fish (Cádiz et al., 2015; present results), indicates that Avt administration activates the pituitary It secretion to modulate physiological functions in the periphery, also suggesting that a negative feedback can be produced in It neurons directly mediated by Avt in combination with It via Itr. Moreover, the subsequent decrease in plasma It concentration, together with the activation of itr mRNA expression at $12 \mathrm{~h}$ post-injection, suggests that plasma It previously secreted from the pituitary gland is being reduced by its binding to specific receptors. In previous studies performed in $S$. aurata juveniles intraperitoneally injected with cortisol, the decrease in plasma It levels was associated with an increase in the expression of the hypothalamic itr (Cádiz et al., 2015). The mechanism underlying this intriguing feature remains unclear, although a possible paracrine/autocrine pathway that interconnects both Avt/It systems, and/or a desensitization of Avt/It receptors to trade off the effect of each hormone when in excess, could not be ruled out. This last hypothesis has been observed in the opercular epithelium of fish, where the double physiological response observed to produce both absorptive and secretive functions in ion trafficking in a timedependent manner mediated by different Avt receptors (MartosSitcha et al., 2015) is missed if It is applied 3-5 min before Avt (Martos-Sitcha and Fuentes, personal observation). Even so, the real binding capacity of Avt to Itr (or vice versa) will need further in vivo and ex vivo experimental approaches to be elucidated. However, taken together, our findings reinforce the idea of an interconnection between vasotocinergic and 
isotocinergic systems, as previously suggested in this (Cádiz et al., 2015) and other species (Batten et al., 1999), to modulate several physiological functions where these pleiotropic hormones are involved.

Previous works have provided indirect evidence for interconnections among Avt/It, HPI, and HPT axes. Axon profiles with immunoreactivity for the neurosecretory peptides vasotocin and isotocin formed large Herring bodies and terminal-like buttons in contact with corticotropic, growth hormone, thyrotropic, and pars intermedia cells (Batten et al., 1999). Our results clearly demonstrate that exogenous cortisol and Avt hormones produce the same type of response in both $c r h$ and $c r h b p$ gene expression, with a clear down-regulation of crh expression, and the absence of variations in crhbp. The similar responses confirm that both cortisol and Avt hormones strongly inhibit the HPI axis at the crh level by negative feedback processes, and hence the stress pathways are differentially sensitive to changes in several hormones expressed independently to perform the same physiological action. Moreover, the effect of cortisol injection in crh mRNA levels was stronger (fourfold decrease) than the response observed after Avt administration. This reinforces the idea that cortisol must be considered the key upstream player of the stress mediated response in fish (Wendelaar Bonga, 1997), in spite of the necessary support of the Avt system depending on the stress source (Mancera et al., 2008; Martos-Sitcha et al., 2013b; Cádiz et al., 2015). The absence of variations in crhbp expression also confirms that the HPI axis needs to be regulated by different pathways. Our results agreed with those of other authors who showed that crhbp expression remained unchanged in response to chronic stress when plasma cortisol levels were high (Wunderink et al., 2011). Moreover, the type (chronic or acute) and source (confinement, environmental, handling, etc.) of stress are very important factors to consider when this complex endocrine axis is examined (Martos-Sitcha et al., 2014b). Recently, it has been demonstrated that cortisol administration produced an important regulation in the vasotocinergic and isotocinergic systems in SW-acclimated gilthead sea breams (Cádiz et al., 2015). Thus, a potential interaction between the vasotocinergic, isotocinergic, and HPI axes was confirmed at the endocrine level through the strong correlation observed between plasma cortisol values and the synthesis (avt and it expression and pituitary storage of mature hormones) and release (plasma values) of Avt/It neuropeptides after hormonal (cortisol) treatment. Moreover, this experimental approach also displayed important effects in other peripheral tissues where Avt and/or It are also involved. Thus, the simulated stress situation produced by cortisol administration suggests a real cooperation

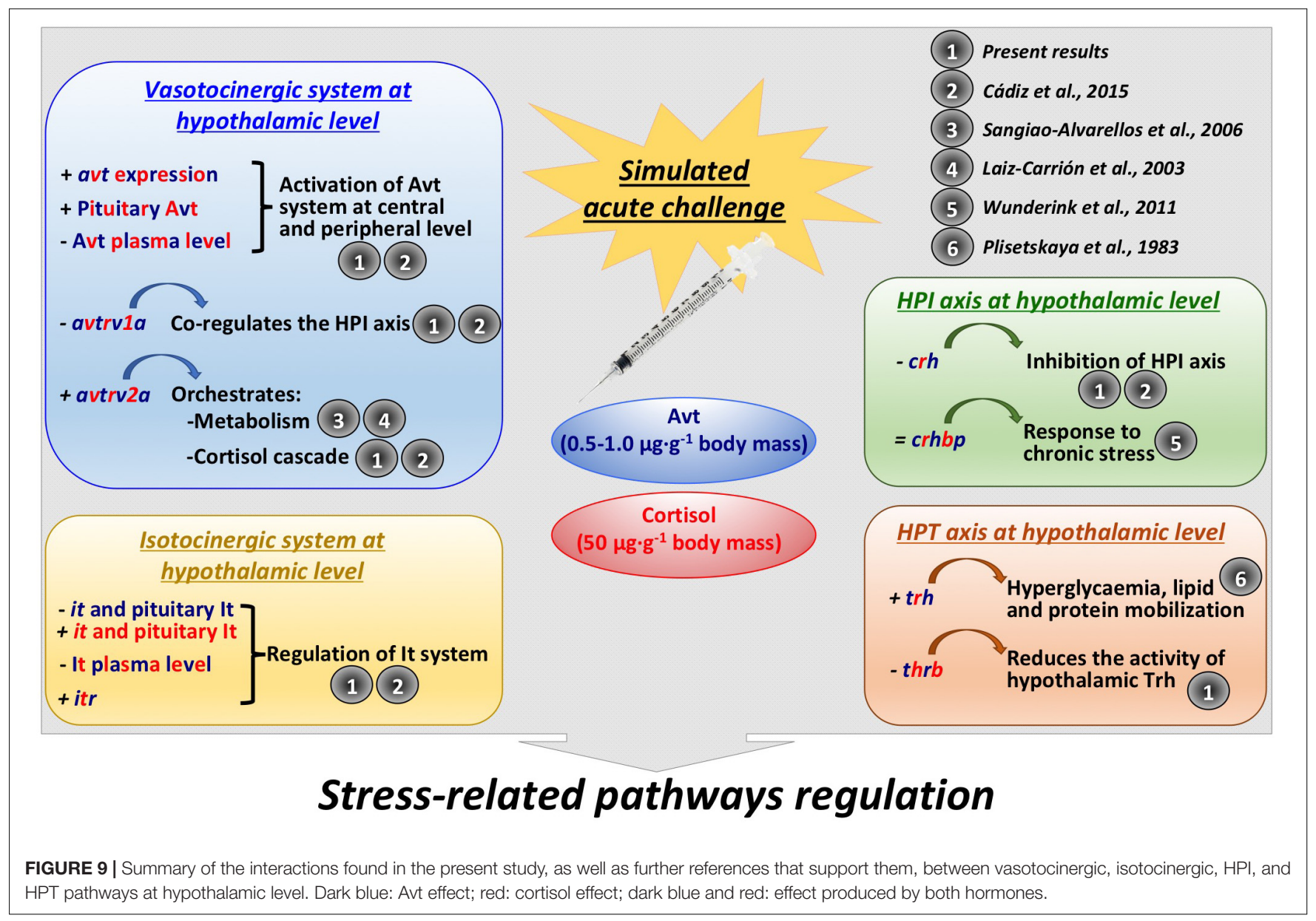


to activate or trade off several physiological actions that can directly or indirectly be mediated by Avt and It receptors, such as those related to hepatic (and hypothalamic) metabolism, branchial regulation of ion trafficking by modulating the action of important ion pumps and transporters, such as $\mathrm{Na}^{+}-\mathrm{K}^{+}$ATPase and Na-K-2Cl co-transporter, or even in feedback mechanisms that orchestrate the synthesis and release of cortisol in the interrenal tissue (see Laiz-Carrión et al., 2003; SangiaoAlvarellos et al., 2006; Martos-Sitcha et al., 2014a, 2015; Cádiz et al., 2015 for review).

In the same way, Avt treatment also produced a transitory increase of plasma cortisol, revealing a first release suppression with the highest dose, followed by a withdrawal and reduction of its levels at the end of the regulatory period (3 days posttreatment). Cortisol was shown to effect self-suppression by negative feedback of its secretion directly at the level of the interrenal gland (Bradford et al., 1992), whereas its regulation could also be carried out at the peripheral level, at least in part, by Avt and/or It receptor genes in this tissue (Cádiz et al., 2015), as strongly suggested by the present results.

Our results also indicate that Avt and cortisol regulates the HPT axis. Both hormonal treatments affected hypothalamic trh and thrb, up-regulating and down-regulating their mRNA expression, respectively. In vertebrates, including fish, Trh acts as a multifunctional hypophysiotropic regulator, stimulating important factors such as Acth and $\alpha$-Msh (Wendelaar Bonga, 1997; Galas et al., 2009). Cortisol and Avt, together with thyroidal hormones, have been demonstrated to participate and share several physiological functions, such as those adaptations caused by several situations, such as osmoregulatory challenges. Altogether, a complex network of interconnections cannot be ruled out, as it has previously been shown for cortisol (Wendelaar Bonga, 1997; Laiz-Carrión et al., 2003; Cádiz et al., 2015) and Avt (Janssens and Lowrey, 1987; Moon and Mommsen, 1990; Sangiao-Alvarellos et al., 2006). Thus, the orchestration of overall physiology by these endocrine players has been historically demonstrated to cause metabolic arrangements related to hyperglycemia, lipid, and protein mobilization (reviewed by Plisetskaya et al., 1983) aimed to activate catabolic routes by operating energy reserves as a secondary stress response in teleost fish (Barton and Iwama, 1991). In addition, these hormonal pathways also affect ion regulation mediated by osmoregulatory peripheral tissues (Sangiao-Alvarellos et al., 2006; Arjona et al., 2008, 2011; McCormick et al., 2008; Ruiz-Jarabo et al., 2017, 2018). Our results support a feedback mechanism in which cortisol and Avt act to reduce the activity of hypothalamic Trh, thus potentially integrating thyrotropic function, which can be achieved up-stream by the thrb in addition to the other factors and receptors described above.

\section{CONCLUSION}

As summarized in Figure 9, this study identified for the first time new evidence regarding an interaction among the vasotocinergic, isotocinergic, interrenal, and thyroid pathways at the hypothalamic level, whose up-stream regulation seems to be orchestrated, at least in part, by the final products of some of them, such as cortisol and Avt. In addition, the interconnection of all of them seems to be thanks to a close participation of specific receptors only present and active at the hypothalamic level which is strongly suggested by the PCA performed. This will modulate the final hormonal release and functioning to trigger and achieve the physiological action required in peripheral tissues, such as metabolism, osmoregulation, and stress-related processes. It is important to closely control this intriguing relationship through a complex net of different hormones and factors synthetized independently, which will trade off and avoid an overload of the physiological function required, since all of them are involved through direct or indirect mechanisms. However, the precise mechanism involved in this complex network of relationships and the way in which these communications are performed remains unclear, and future analyses are needed to determine whether the final biological function is produced after a specific stimulation or inhibition of these endocrine systems.

\section{AUTHOR CONTRIBUTIONS}

JM-S and JM conceived and designed the study. JM-S, LC, and GM-R carried out experimental procedures and analyzed transcriptomic data. MG and EK analyzed Avt and It content in plasma and pituitary. JM-S, LC, and JM wrote the original draft. All authors interpreted the data and reviewed, edited, and approved the final manuscript.

\section{FUNDING}

This study was funded by projects AGL2013-48835-C2-1-R from the Spanish Ministry of Economic Affairs and Competitiveness (MINECO, Spanish Government) to JM (Spain) and 498/NHISZP-JPR/2009/0 to EK (Poland). JM-S and JM belong to the Fish Welfare and Stress Network (AGL2016-81808-REDT), supported by MINECO.

\section{ACKNOWLEDGMENTS}

The authors wish to thank Servicios Centrales de Investigación en Cultivos Marinos (SCI-CM, CASEM, University of Cádiz, Cádiz, Spain) for providing experimental fish, Mrs. María Francisca Osta and Mr. Juan José Blanco for their excellent technical assistance, and Prof. Dr. Stephen D. McCormick for his critical review of the manuscript. Experiment has been carried out at the Campus de Excelencia Internacional del Mar (CEI-MAR) facilities from the University of Cádiz and ICMAN-CSIC.

\section{SUPPLEMENTARY MATERIAL}

The Supplementary Material for this article can be found online at: https://www.frontiersin.org/articles/10.3389/fphys.2019. 00261/full\#supplementary-material 


\section{REFERENCES}

Agirregoitia, N., Laiz-Carriòn, R., Varona, A., Martín, M. P., Mancera, J. M., and Irazusta, J. (2005). Distribution of peptidase activity in teleost and rat tissues. J. Comp. Physiol. B 175, 433-444. doi: 10.1007/s00360-005-0011-5

Almeida, O., Gozdowska, M., Kulczykowska, E., and Oliveira, R. F. (2012). Brain levels of arginine-vasotocin and isotocin in dominant and subordinate males of a cichlid fish. Horm. Behav. 61, 212-217. doi: 10.1016/j.yhbeh.2011.12.008

Aluru, N., and Vijayan, M. M. (2008). Molecular characterization, tissue-specific expression, and regulation of melanocortin 2 receptor in rainbow trout. J. Endocrinol. 149, 4577-4588. doi: 10.1210/en.2008-0435

Amer, S., and Brown, J. A. (1995). Glomerular actions of arginine vasotocin in the in situ perfused trout kidney. Am. J. Physiol. 269, R775-R780. doi: 10.1152/ ajpregu.1995.269.4.R775

Antoni, F. A. (1984). Novel ligand specificity of pituitary vasopressin receptors in the rat. Neuroendocrinology 39, 186-188. doi: 10.1159/000123976

Arends, R. J., Mancera, J. M., Muñoz, J. L., Wendelaar Bonga, S. E., and Flik, G. (1999). The stress response of the gilthead sea bream (Sparus aurata L.) to air exposure and confinement. J. Endocrinol. 163, 149-157. doi: 10.1677/joe.0. 1630149

Arjona, F. J., Vargas-Chacoff, L., Martín del Río, M. P., Flik, G., Mancera, J. M., and Klaren, P. H. M. (2008). The involvement of thyroid hormones and cortisol in the osmotic acclimation of Solea senegalensis. Gen. Comp. Endocrinol. 155, 796-803. doi: 10.1016/j.ygcen.2007.09.007

Arjona, F. J., Vargas-Chacoff, L., Martin del Río, M. P., Flik, G., Mancera, J. M., and Klaren, P. H. (2011). Effects of cortisol and thyroid hormone on peripheral outer ring deiodination and osmoregulatory parameters in the Senegalese sole (Solea senegalensis). J. Endocrinol. 208, 323-330. doi: 10.1530/JOE-10-0416

Balment, R. J., Lu, W., Weybourne, E., and Warne, J. M. (2006). Arginine vasotocin a key hormone in fish physiology and behaviour: a review with insights from mammalian models. Gen. Comp. Endocrinol. 147, 9-16. doi: 10.1016/j.ygcen. 2005.12.022

Barton, B. A., and Iwama, G. K. (1991). Physiological changes in fish from stress in aquaculture with emphasis on the response and effects of corticosteroids. Ann. Rev. Fish Dis. 1, 3-26. doi: 10.1016/0959-8030(91)90019-G

Batten, T. F. C., Moons, L., and Vandesande, F. (1999). Innervation and control of the adenohypophysis by hypothalamic peptidergic neurons in teleost fishes: EM immunohistochemical evidence. Microsci. Res. Tech. 44, 19-35. doi: 10.1002/ (SICI)1097-0029(19990101)44:1<19::AID-JEMT4>3.0.CO;2-L

Bernier, N. J., Flik, G., and Klaren, P. H. M. (2009). "Chapter 6 Regulation And Contribution Of Corticotropic, Melanotropic And Thyrotropic Axes To The Stress Response In Fishes," in Fish Neuroendocrinology, eds N. J. Bernier, G. Van Der Kraak, A. P. Farrell, and C. J. Brauner (Cambridge: Academic Press), 235-311. doi: 10.1016/S1546-5098(09)28006-X

Bradford, C. S., Fitzpatrick, M. S., and Schreck, C. B. (1992). Evidence for ultra-short-loop feedback in ACTH-induced interrenal steroidogenesis in coho salmon: acute self-suppression of cortisol secretion in vitro. Gen. Comp. Endocrinol. 87, 292-299. doi: 10.1016/0016-6480(92)90034-H

Cádiz, L., Román-padilla, J., Gozdowska, M., Kulczykowska, E., Martínezrodríguez, G., Mancera, J. M., et al. (2015). Cortisol modulates vasotocinergic and isotocinergic pathways in the gilthead sea bream. J. Exp. Biol. 218, 1-10. doi: 10.1242/jeb.113944

Chatterjee, A., Hsieh, Y. L., and Yu, J. Y. (2001). Molecular cloning of cDNA encoding thyroid stimulating hormone beta subunit of bighead carp Aristichthys nobilis and regulation of its gene expression. Mol. Cell. Endocrinol. 174, 1-9. doi: 10.1016/S0303-7207(01)00392-6

Dange, A. D. (1986). Branchial $\mathrm{Na}+/ \mathrm{K}+-$ ATPase activity in freshwater and seawater acclimated tilapia Oreochromis mossambicus: effects of cortisol and thyroxine. Gen. Comp. Endocrinol. 62, 341-343. doi: 10.1016/0016-6480(86) 90125-5

De Groef, B., Van Der Geyten, S., Darras, V. M., and Kühn, E. R. (2006). Role of corticotropin-releasing hormone as a thyrotropin-releasing factor in nonmammalian vertebrates. Gen. Comp. Endocrinol. 146, 62-68. doi: 10.1016/j. ygcen.2005.10.014

de Jesus, E. G., Inui, Y., and Hirano, T. (1990). Cortisol enhances the stimulating action of thyroid hormones on dorsal fin-ray resorption of flounder larvae in vitro. Gen. Comp. Endocrinol. 79, 167-173. doi: 10.1016/0016-6480(90) 90101-Q
Flik, G., Klaren, P. H. M., Van Den Burg, E. H., Metz, J. R., and Huising, M. O. (2006). CRF and stress in fish. Gen. Comp. Endocrinol. 146, 36-44. doi: 10.1016/ j.ygcen.2005.11.005

Galas, L., Raoult, E., Tonon, M. C., Okada, R., Jenks, B. G., Castaño, J. P., et al. (2009). TRH acts as a multifunctional hypophysiotropic factor in vertebrates. Gen. Comp. Endocrinol. 164, 40-50. doi: 10.1016/j.ygcen.2009. 05.003

Geven, E. J. W., Flik, G., and Klaren, P. H. M. (2009). Central and peripheral integration of interrenal and thyroid axes signals in common carp (Cyprinus carpio L.). J. Endocrinol. 200, 117-123. doi: 10.1677/JOE-08-0410

Geven, E. J. W., Verkaar, F., Flik, G., and Klaren, P. H. M. (2006). Experimental hyperthyroidism and central mediators of stress axis and thyroid axis activity in common carp (Cyprinus carpio L.). J. Mol. Endocrinol. 37, 443-452. doi: 10.1677/jme.1.02144

Goossens, N., Dierickx, K., and Vandesande, F. (1977). Immunocytochemical localization of vasotocin and isotocin in the preopticohypophysial neurosecretory system of teleosts. Gen. Comp. Endocrinol. 32, 371-375. doi: 10.1016/0016-6480(77)90216-7

Gorbman, A., Dickoff, W. W., Vigna, S. R., Clark, N. B., and Ralph, C. L. (1983). Comparative Endocrinology. New York, NY: John Wiley and Sons, Inc.

Gozdowska, M., Kleszczyńska, A., Sokołowska, E., and Kulczykowska, E. (2006). Arginine vasotocin (AVT) and isotocin (IT) in fish brain: diurnal and seasonal variations. Comp. Biochem. Physiol. 143, 330-334. doi: 10.1016/j.cbpb.2005. 12.004

Han, Y. S., Liao, I. C., Tzeng, W. N., and Yu, J. Y. (2004). Cloning of the cDNA for thyroid stimulating hormone beta subunit and changes in activity of the pituitary-thyroid axis during silvering of the japanese eel, Anguilla japonica. J. Mol. Endocrinol. 32, 179-194. doi: 10.1677/jme.0.0320179

Henderson, I. W., and Garland, H. O. (1980). "The interrenal gland in piscis. Part 2. Physiology," in General, Comparative and Clinical Endocrinology of the Adrenal Cortex, eds I. Chester Jones and I. W. Henderson (New York, NY: Academy Press), 473-523.

Huising, M. O., Metz, J. R., van Schooten, C., Taverne-Thiele, A. J., Hermsen, T., Verburg-van Kemenade, B. M. L., et al. (2004). Structural characterisation of a cyprinid (Cyprinus carpio L.) CRH, CRH-BP and CRH-R1, and the role of these proteins in the acute stress response. J. Mol. Endocrinol. 32, 627-648. doi: 10.1677/jme.0.0320627

Janssens, P. A., and Lowrey, P. (1987). Hormonal regulation of hepatic glycogenolysis in the carp, Cyprinus carpio. Am. J. Physiol. 252, R653-R660. doi: 10.1152/ajpregu.1987.252.4.R653

Kleszczyńska, A., Sokołowska, E., and Kulczykowska, E. (2012). Variation in brain arginine vasotocin (AVT) and isotocin (IT) levels with reproductive stage and social status in males of three-spined stickleback (Gasterosteus aculeatus). Gen. Comp. Endocrinol. 175, 290-296. doi: 10.1016/j.ygcen.2011. 11.022

Kulczykowska, E. (2007). "Arginine vasotocin and isotocin: towards their role in fish osmoregulation," in Fish Osmoregulation, eds B. Baldisserotto, J. M. Mancero Romero, and B. G. Kapoor (Enfield, NH: Science Publisher), 151-176. doi: 10.1201/b10994-7

Laiz-Carrión, R., Guerreiro, P. M., Fuentes, J., Canário, A. V. M., Martín Del Río, M. P., and Mancera, J. M. (2005). Branchial osmoregulatory response to salinity in the gilthead sea bream, Sparus auratus. J. Exp. Zool. A 303, 563-576. doi: 10.1002/jez.a.183

Laiz-Carrión, R., Martín Del Río, M. P., Miguez, J. M., Mancera, J. M., and Soengas, J. L. (2003). Influence of cortisol on osmoregulation and energy metabolism in gilthead seabream Sparus aurata. J. Exp. Zool. A Comp. Exp. Biol. 298A, 105-118. doi: 10.1002/jez.a.10256

Laiz-Carrión, R., Sangiao-Alvarellos, S., Guzmán, J. M., Martín del Río, M. P., Míguez, J. M., Soengas, J. L., et al. (2002). Energy metabolism in fish tissues related to osmoregulation and cortisol action. Fish Physiol. Biochem. 27, 179-188. doi: 10.1023/B:FISH.0000032725.96481.b8

Larsen, D. A., Swanson, P., Dickey, J. T., Rivier, J., and Dickhoff, W. W. (1998). In vitro thyrotropin-releasing activity of corticotropin-releasing hormonefamily peptides in coho salmon, Oncorhynchus kisutch. Gen. Comp. Endocrinol. 109, 276-285. doi: 10.1006/gcen.1997.7031

Livak, K. J., and Schmittgen, T. D. (2001). Analysis of relative gene expression data using real-time quantitative PCR and the $2^{-\Delta \Delta C}$ T method. Methods 25 , 402-408. doi: 10.1006/meth.2001.1262 
Mancera, J. M., Laiz-Carrión, R., and Martín del Río, M. P. (2002). Osmoregulatory action of PRL, GH, and cortisol on the gilthead seabream (Sparus aurata L.). Gen. Comp. Endocrinol. 129, 95-103. doi: 10.1016/S0016-6480(02)00 522-1

Mancera, J. M., and McCormick, S. D. (2007). "Role of prolactin, growth hormone, insuline-like growth factor I and cortisol in teleost osmoregulation," in Fish Osmoregulation, eds B. Baldisserotto, J. M. Mancera, and B. G. Kapoor (Enfield NH: Science Publishers), 497-515.

Mancera, J. M., Vargas-Chacoff, L., García-López, A., Kleszczyńska, A., Kalamarz, H., Martínez-Rodríguez, G., et al. (2008). High density and food deprivation affect arginine vasotocin, isotocin and melatonin in gilthead sea bream (Sparus auratus). Comp. Biochem. Physiol. A Mol. Integr. Physiol. 149, 92-97. doi: 10.1016/j.cbpa.2007.10.016

Martos-Sitcha, J. A., Fuentes, J., Mancera, J. M., and Martínez-Rodríguez, G. (2014a). Variations in the expression of vasotocin and isotocin receptor genes in the gilthead sea bream Sparus aurata during different osmotic challenges. Gen. Comp. Endocrinol. 197, 5-17. doi: 10.1016/j.ygcen.2013.11.026

Martos-Sitcha, J. A., Wunderink, Y. S., Straatjes, J., Skrzynska, A. K., Mancera, J. M., and Martínez-Rodríguez, G. (2014b). Different stressors induce differential responses of the CRH-stress system in the gilthead sea bream (Sparus aurata). Comp. Biochem. Physiol. -Part A Mol. Integr. Physiol. 177, 49-61. doi: 10.1016/ j.cbpa.2014.07.021

Martos-Sitcha, J. A., Gregório, S. F., Carvalho, E. S. M., Canario, A. V. M., Power, D. M., Mancera, J. M., et al. (2013a). AVT is involved in the regulation of ion transport in the intestine of the sea bream (Sparus aurata). Gen. Comp. Endocrinol. 193, 221-228. doi: 10.1016/j.ygcen.2013.07.017

Martos-Sitcha, J. A., Wunderink, Y. S., Gozdowska, M., Kulczykowska, E., Mancera, J. M., and Martínez-Rodríguez, G. (2013b). Vasotocinergic and isotocinergic systems in the gilthead sea bream (Sparus aurata): an osmoregulatory story. Comp. Biochem. Physiol. A Mol. Integr. Physiol. 166, 571-581. doi: 10.1016/j.cbpa.2013.09.001

Martos-Sitcha, J. A., Martínez-Rodríguez, G., Mancera, J. M., and Fuentes, J. (2015). AVT and IT regulate ion transport across the opercular epithelium of killifish (Fundulus heteroclitus) and gilthead sea bream (Sparus aurata). Comp. Biochem. Physiol. Part A Mol. Integr. Physiol. 182, 93-101. doi: 10.1016/j.cbpa. 2014.12.027

McCormick, S. D. (1995). "Hormonal control of gill Na+,K+-ATPase and chloride cell function," in Fish Physiology, eds C. M. Wood and T. J. Shut-tlewoth (San Diego: Academic Press).

McCormick, S. D., Regish, A., O’Dea, M. F., and Shrimpton, J. M. (2008). Are we missing a mineralocorticoid in teleost fish? Effects of cortisol, deoxycorticosterone and aldosterone on osmoregulation, gill $\mathrm{Na}^{+}, \mathrm{K}^{+}$-ATPase activity and isoform mRNA levels in Atlantic salmon. Gen. Comp. Endocrinol. 157, 35-40. doi: 10.1016/j.ygcen.2008.03.024

Mommsen, T. P., Vijayan, M. M., and Moon, T. W. (1999). Cortisol in teleosts: dynamics, mechanisms of action, and metabolic regulation. Rev. Fish Biol. Fish. 9, 211-268. doi: 10.1023/A:1008924418720

Moon, T. W., and Mommsen, T. P. (1990). Vasoactive peptides and phenylephrine actions in isolated teleost hepatocytes. Am. J. Physiol. 259, E644-E649. doi: 10.1152/ajpendo.1990.259.5.E644

Moons, L., Cambre, M., Batten, T. F. C., and Vandesande, F. (1989). Autoradiographic localization of binding sites for vasotocin in the brain and pituitary of the sea bass (Dicentrarchus labrax). Neurosci. Lett. 100, 11-16. doi: 10.1016/0304-3940(89)90652-6

Norris, D. O. (1997). Vertebrate Endocrinology. San Diego: Academic Press.

Peter, M. S., and Peter, V. S. (2009). Action of thyroid inhibitor propyl thiouracil on thyroid and interrenal axes in the freshwater tilapia, Oreochromis mossambicus. Endocrinol. Reprod 13, 37-44.

Peter, R. E. (1977). The preoptic nucleus in fishes: comparative discussion of function-activity relationships. Am. Zool. 17, 775-785. doi: 10.1093/icb/17. 4.775

Plisetskaya, E., Woo, N. Y., and Murat, J. C. (1983). Thyroid hormones in cyclostomes and fish and their role in regulation of intermediary metabolism. Comp. Bioch. Physiol. A Physiol. 74, 179-187. doi: 10.1016/0300-9629(83) 90586-8

Priborsky, J., and Velisek, J. (2018). A Review of three commonly used fish anesthetics. Rev. Fish. Sci. Aquac. 26, 417-442. doi: 10.1080/23308249.2018. 1442812
Redding, J. M., Leloup-Hatey, J., and Leloup, J. (1986). Suppression of plasma thyroid hormone concentrations by cortisol in the european eel Anguilla anguilla. Comp. biochem. Physiol. A 83, 409-413. doi: 10.1016/0300-9629(86) 90124-6

Ruiz-Jarabo, I., Klaren, P. H., Louro, B., Martos-Sitcha, J. A., Pinto, P. I. S., VargasChacoff, L., et al. (2017). Characterization of the peripheral thyroid system of gilthead seabream acclimated to different ambient salinities. Comp. Biochem. Physiol. Part A Mol. Integr. Physiol. 203, 24-31. doi: 10.1016/j.cbpa.2016. 08.013

Ruiz-Jarabo, I., Martos-Sitcha, J. A., Barragán-Méndez, C., Martínez-Rodríguez, G., Mancera, J. M., and Arjona, F. J. (2018). Gene expression of thyrotropin- and corticotrophin-releasing hormones is regulated by environmental salinity in the euryhaline teleost Sparus aurata. Fish Physiol. Biochem. 44, 615-628. doi: 10.1007/s10695-017-0457-x

Sangiao-Alvarellos, S., Laiz-Carrión, R., Guzmán, J. M., Martín del Río, M. P., Miguez, J. M., Mancera, J. M., et al. (2003). Acclimation of S. aurata to various salinities alters energy metabolism of osmoregulatory and nonosmoregulatory organs. Am. J. Physiol. Regul. Integr. Comp. Physiol. 285, R897-R907. doi: 10. 1152/ajpregu.00161.2003

Sangiao-Alvarellos, S., Lapido, M., Miguez, J. M., and Soengas, J. L. (2004). Effects of central administration of arginine vasotocin on monoaminergic neurotransmitters and energy metabolism of rainbow trout brain. J. Fish Biol. 64, 1313-1329. doi: 10.1111/j.0022-1112.2004.00394.x

Sangiao-Alvarellos, S., Polakof, S., Arjona, F. J., Kleszczynska, A., Martín del Río, M. P., Míguez, J. M., et al. (2006). Osmoregulatory and metabolic changes in the gilthead sea bream Sparus auratus after arginine vasotocin (AVT) treatment. Gen. Comp. Endocrinol. 148, 348-358. doi: 10.1016/j.ygcen.2006. 04.005

Sherwani, F. A., and Parwez, I. (2008). Plasma thyroxine and cortisol profiles and gill and kidney $\mathrm{Na}+/ \mathrm{K}+$-ATPase and SDH activities during acclimation of the catfish Heteropneustes fossilis (bloch) to higher salinity, with special reference to the effects of exogenous cortisol on hypo-osmoregul. Zool. Sci. 25, 164-171. doi: $10.2108 /$ zsj.25.164

Shrimpton, J. M., and McCormick, S. D. (1998). Regulation of gill cytosolic corticosteroid receptors in juvenile atlantic salmon: interaction effects of growth hormone with prolactin and triodothyronine. Gen. Comp. Endocrinol. 112, 262-274. doi: 10.1006/gcen.1998.7172

Skrzynska, A. K., Gozdowska, M., Kulczykowska, E., Martínez-Rodríguez, G., Mancera, J. M., and Martos-Sitcha, J. A. (2017). The effect of starvation and refeeding on vasotocinergic and isotocinergic pathways in immature gilthead sea bream (Sparus aurata). J. Comp. Physiol. B 187, 945-958. doi: 10.1007/s00360017-1064-y

Skrzynska, A. K., Maiorano, E., Bastaroli, M., Naderi, F., Míguez, J. M., MartínezRodríguez, G., et al. (2018a). Impact of air exposure on vasotocinergic and isotocinergic systems in gilthead sea bream (Sparus aurata): New insights on fish stress response. Front. Physiol. 9:96. doi: 10.3389/fphys.2018. 00096

Skrzynska, A. K., Martos-Sitcha, J. A., Martínez-Rodríguez, G., and Mancera, J. M. (2018b). Unraveling vasotocinergic, isotocinergic and stress pathways after food deprivation and high stocking density in the gilthead sea bream. Comp. Biochem. Physiol. Part A Mol. Integr. Physiol. 215, 35-44. doi: 10.1016/j.cbpa. 2017.10.012

Sower, S. A., Freamat, M., and Kavanaugh, S. I. (2009). The origins of the vertebrate hypothalamic-pituitary-gonadal (HPG) and hypothalamicpituitary-thyroid (HPT) endocrine systems: new insights from lampreys. Gen. Comp. Endocrinol. 161, 20-29. doi: 10.1016/j.ygcen.2008. 11.023

Toni, C., Martos-Sitcha, J. A., Baldisserotto, B., Heinzmann, B. M., de Lima Silva, L., Martínez-Rodríguez, G., et al. (2015). Sedative effect of 2phenoxyethanol and essential oil of Lippia alba on stress response in gilthead sea bream (Sparus aurata). Res. Vet. Sci. 103, 20-27. doi: 10.1016/j.rvsc.2015. 09.006

van den Dungen, H. M., Buijs, R. M., Pool, C. W., and Terlou, M. (1982). The distribution of vasotocin and isotocin in the brain of the rainbow trout. J. Comp. Neurol. 212, 146-157. doi: 10.1002/cne.902120205

Vijayan, M. M., and Leatherland, J. F. (1988). Effect of stocking density on the growth and stress-response in brook charr, Salvelinus fontinalis. Aquaculture 75, 159-170. doi: 10.1016/0044-8486(88)90029-4 
Warne, J. M., Harding, K. E., and Balment, R. J. (2002). Neurohypophysial hormones and renal function in fish and mammals. Comp. Biochem. Physiol. B Biochem. Mol. Biol. 132, 231-237. doi: 10.1016/S1096-4959(01)00 527-9

Wendelaar Bonga, S. E. (1997). The stress response in fish. Physiol. Rev. 77, 591-625. doi: 10.1152/physrev.1997.77.3.591

Wunderink, Y. S., Engels, S., Halm, S., Yúfera, M., Martínez-Rodríguez, G., Flik, G., et al. (2011). Chronic and acute stress responses in Senegalese sole (Solea senegalensis): The involvement of cortisol, CRH and CRHBP. Gen. Comp. Endocrinol. 171, 203-210. doi: 10.1016/j.ygcen.2011. 01.010
Conflict of Interest Statement: The authors declare that the research was conducted in the absence of any commercial or financial relationships that could be construed as a potential conflict of interest.

Copyright (ㄷ 2019 Martos-Sitcha, Cádiz, Gozdowska, Kulczykowska, MartínezRodriguez and Mancera. This is an open-access article distributed under the terms of the Creative Commons Attribution License (CC BY). The use, distribution or reproduction in other forums is permitted, provided the original author(s) and the copyright owner(s) are credited and that the original publication in this journal is cited, in accordance with accepted academic practice. No use, distribution or reproduction is permitted which does not comply with these terms. 